\title{
Preparing for the unknown: How working memory provides a link between perception and anticipated action
}

Marlene Rösner*, Melinda Sabo, Laura Klatt, Edmund Wascher \& Daniel Schneider Leibniz Research Centre for Working Environment and Human Factors

* Address of correspondence:

Marlene Rösner

Leibniz Research Centre for Working Environment and Human Factors

Ardeystraße 67

44139 Dortmund

Germany

E-mail: roesner@ifado.de 


\begin{abstract}
What mechanisms underlie the transfer of a working memory representation into a higher-level code for guiding future actions? Electrophysiological correlates of attentional selection and motor preparation processes within working memory were investigated in two retrospective cuing tasks. In the first experiment, participants stored the orientation and location of a grating. Subsequent feature cues (selective vs. neutral) indicated which feature would be the target for later report. The oscillatory response in the mu and beta frequency range with an estimated source in the sensorimotor cortex contralateral to the responding hand was used as correlate of motor preparation. Mu/beta suppression was stronger following the selective feature cues compared to the neutral cue, demonstrating that purely feature-based selection is sufficient to form a prospective motor plan. In the second experiment, another retrospective cue was included to study whether knowledge of the task at hand is necessary to initiate motor preparation. Following the feature cue, participants were cued to either compare the stored feature(s) to a probe stimulus (recognition task) or to adjust the memory probe to match the target feature (continuous report task). An analogous suppression in the mu frequency range was observed following a selective feature cue, even though the task at hand was not specified yet. Further, a subsequent selective task cue again elicited a mu/beta suppression, which was stronger after a continuous report task cue. This indicates that working memory is able to flexibly store different types of information in higher-level mental codes to provide optimal prerequisites for all required action possibilities.
\end{abstract}

Key words: Working memory, motor planning, selective attention, neural oscillations, $\mathrm{mu} /$ beta suppression 


\section{Introduction}

In everyday life, we are frequently required to respond to stimuli that are present in our environment. However, what feels natural and automatic, requires a complex cascade of cognitive processes, ranging from sensory perception via motor planning to motor execution. Working memory plays a central role in these cognitive processes, as it can be defined as a cognitive stage for the interface between perceptual information, higher-level cognitive operations, and goal-directed actions. Based on two working memory experiments and neural oscillations measured by means of the EEG, this study examined the role of prospective motor plans for the focusing of attention within working memory.

Traditionally, perception and action have been considered to occur in a capacity-limited, strictly-serial fashion (Pashler, 1994). In this view, attention acts as a kind of spotlight by enhancing the mental representation of relevant information and potentially suppressing neural activity related to irrelevant content. Analogously, during the storage of visuo-spatial information in working memory, we can focus attention on certain stored content and thereby generate a prioritized representational state, protecting the attended information against decay and interference (Bays \& Taylor, 2018; Makovski et al., 2008; Matsukura et al., 2007; Pertzov et al., 2013). However, this concept of an attentional bias on information stored in working memory fails to consider the goal-directedness of human information processing in every-day life. What we store in working memory is not only the mental representation of past sensory input, but also information about what current goal we are pursuing or what future action or mental operation we want to perform. Thus, working memory contents cannot only be seen as more or less precise copies of sensory information, but rather as mental representations that can be used to guide future action (for review: Nobre \& Stokes, 2019; Olivers \& Roelfsema, 2020).

In line with this account, earlier studies have shown that, just as storing sensory representations, working memory can also store higher-level representations of to-be- 
executed actions (e.g. Behmer \& Fournier, 2014; Gallivan et al., 2016; Schneider et al., 2020; Zickerick et al., 2020). The attentional selection of certain working memory content could be the result of linking a sensory representation to such a representation of a to-be-executed action (Olivers \& Roelfsema, 2020). In this regard, the measurement of neural oscillations in the EEG as a correlate for motor planning (Leocani et al., 1997; Pfurtscheller et al., 2000; Zhuang et al., 1997) can provide valuable information. For example, an investigation by Schneider, Barth, \& Wascher (2017) required participants to remember three different stimulus orientations. Subsequently, they were cued to focus on one, two or three items for later orientation report. The authors observed a suppression of higher-alpha or mu $(\sim 10-12$ $\mathrm{Hz})$ and beta oscillatory power $(\sim 20-24 \mathrm{~Hz})$ with an estimated source in the pre-motor and motor cortex contralateral to the side of the to-be-executed action (i.e., moving a computer mouse with the right arm for adjusting a probe stimulus to the cued orientation). This effect was only found when one item was cued (i.e., when the to-be-reported orientation was welldefined) and it appeared clearly prior to the presentation of the memory probe demanding the orientation adjustment. In a comparable way, van Ede and colleagues (2019) used non-spatial (color) information to cue relevant working memory content. They orthogonally manipulated the lateralized position of the relevant visual item in a memory array (left vs. right target) and the required motor response (button press with left vs. right index finger). Hemispheric asymmetries in alpha oscillations related to attentional selection (Foxe \& Snyder, 2011; Händel et al., 2011; Myers et al., 2015; Sauseng et al., 2005; Schneider et al., 2016) and in mu and beta oscillations related to planning a left- vs. right-handed response could thus be fully separated from one another. It was shown that these types of oscillatory effects were related to spatially distinct areas of the brain, but occurred in the same time frame. These results highlight that working memory can store sensory information along with corresponding motor plans and that both memory codes can be selected in support of future behavior (see also: Boettcher et al., 2021). 
To our knowledge, however, no study has yet investigated whether the same principle applies when a working memory task requires the selection of individual features of a single visual object for subsequent report. Therefore, as a first step, the current study investigated to what extent feature selection in working memory also involves the selection of prospective motor plans. For this purpose, participants had to store both the location and orientation of a single object in working memory and were then cued to focus on one of these features for later report. We expected that both selective cues should lead to a more accurate report relative to a neutral cue condition without an attentional bias towards either feature. Furthermore, if selecting a visual feature from an object stored in working memory also involved the selection of an associated motor code, we should observe stronger suppression of oscillatory mu and beta power with an estimated source in the pre-motor cortex contralateral (but not ipsilateral) to the to-be-executed response for the selective cue conditions relative to the neutral condition. This effect should occur together with a stronger suppression of alpha power over posterior visual areas following the selective cues that was already observed in the context of the retrospective selection of visual object features (see Hajonides et al., 2020; Niklaus et al., 2017; Sasin \& Fougnie, 2020; Ye et al., 2016).

In a second experiment, we wanted to build on this by asking what conditions must be met for a prospective motor code to get created in working memory. For example, a motor representation could be created only if it is clearly defined that the next operation in a working memory task requires dealing with the stored information based on a certain movement (e.g., adjusting a memory probe orientation or moving the hand or gaze to a specific position). This was always the case in the studies that used mu and beta oscillations as a correlate of prospective motor plans during working memory storage (Boettcher et al., 2021; Schneider et al., 2017; van Ede et al., 2019). Alternatively, it is possible that a motor representation of task-relevant working memory content is created even if the upcoming task has not yet been clearly defined. Working memory could then flexibly select from the stored 
mental representations of a given content the one(s) best suited to support each subsequent operation. Participants therefore had to select the relevant information in working memory on the basis of a feature cue (location vs. orientation vs. neutral) and later use it either for a continuous report task (adjusting a memory probe to the target feature by moving the computer mouse) or a recognition task (match vs. mismatch decision based on a memory probe). Only a second retro-cue (continuous report vs. recognition) or the later memory probe display (following a neutral task cue) indicated which of the two tasks should be performed based on the selected information. We hypothesized that a motor code of the selected information should be pre-emptively created in working memory even if the task to be performed has not yet been clearly defined. In this case, a greater suppression of mu and beta power in contralateral sensorimotor and pre-motor cortex after the selective feature cues (i.e., before the definition of the task to be performed) relative to the neutral condition should be evident as a correlate of motor selection. A further selection of the mental representations useful for the to-be-executed task should then take place after the (second) task retro-cue. Compared to the recognition task which should first require comparing the memory probe to the relevant visual feature before selecting a certain response, cuing the continuous report task should entail a motor-planning process ahead of memory probe presentation, reflected by a stronger suppression of mu and beta power in contralateral sensorimotor and pre-motor cortex. These results would argue for a flexible use of sensory and motor codes in working memory according to the requirements of the tasks to be performed.

\section{Materials and methods}

\subsection{Participants}

Twenty-four participants took part in the first experiment (15 females), who were between 20 and 30 years old $(M=24.13, S D=3.03)$ and right-handed (as assessed with the Edinburgh Handedness Inventory: Oldfield, 1971). Twenty-six participants took part in the second experiment. Due to performance below chance level $(n=3)$ and one participant 
actually being left-handed, four participants had to be excluded. The final sample thus consisted of 22 right-handed participants (age: $M=23.09, S D=2.43$, range $=19-27,19$ female). None of the participants from the first and second experiment reported suffering from any neurological or psychological disorder. Participation was compensated with 10 Euros/hour or with course credits (for psychology students). The experiments were approved by the local ethics committee of the Leibniz Research Centre for Working Environment and Human Factors (Dortmund, Germany) and were conducted in accordance with the Declaration of Helsinki.

\subsection{Stimuli and procedure}

The experiments took place in an electrically shielded, dimly lit chamber. Participants were seated with a viewing distance of $150 \mathrm{~cm}$ from the 22-inch CRT monitor (1024x768 pixels), which had a $100 \mathrm{~Hz}$ refresh rate. A ViSaGe MKII Stimulus Generator (Cambridge Research Systems, Rochester, UK) controlled stimulus presentation.

Prior to the actual experiments, participants performed a short training and three practice blocks to get acquainted with the tasks. During the training, a grey circle (luminance $=20 \mathrm{~cd} / \mathrm{m}^{2}, \mathrm{RGB}=[\mathrm{R} 54 \mathrm{G} 54 \mathrm{~B} 54]$, diameter $\left.=4.4^{\circ}\right)$ was presented on the left side of the screen. A randomly oriented Gabor grating $\left(\right.$ size $=1.3^{\circ}$, spatial frequency $=4.25$ cycles per degree, phase $=180^{\circ}$, deviation $=0.25^{\circ}$ ) was shown on the perimeter of the circle on a random position. On the right side, a similar second circle with either one bar (indicating a position report) or two opposing bars (indicating an orientation report) was shown. The participants' task was to adjust the second circle, using lateral mouse movements, so that the $\operatorname{bar}(\mathrm{s})$ matched the position or the orientation of the Gabor grating. In cases when the adjustment took longer than $4 \mathrm{~s}$, participants were instructed to respond faster in order to familiarize themselves with the time constrains of the later experiment. The training was complete when the average response error was below $18^{\circ}$ for orientation and below $36^{\circ}$ for 
bioRxiv preprint doi: https://doi.org/10.1101/2022.01.25.477681; this version posted January 27,2022 . The copyright holder for this preprint (which was not certified by peer review) is the author/funder, who has granted bioRxiv a license to display the preprint in perpetuity. It is made available under aCC-BY-NC-ND 4.0 International license.

location in 50 consecutive trials. Afterwards, participants performed three practice blocks (30 trials each), one for each condition of the experiment (see below).

\subsubsection{Experiment 1}

Participants were instructed to memorize the orientation and location of an oriented Gabor grating (similar to the one in the training; 16 different possible locations $22.5^{\circ}$ apart from each other; eight different possible orientations $22.5^{\circ}$ apart from each other), depicted on the perimeter of an imaginary centrally located circle $\left(\right.$ diameter $\left.=4.4^{\circ}\right)$. After a $1500 \mathrm{~ms}$ delay interval, a retrospective feature cue indicated whether participants would have to recall the location (location cue: "P" for "Position"; one third of the trials) or orientation (orientation cue:", "O"; one third of the trials) of the initially presented grating (see figure 1A). In one third of the trials, the feature cue contained no information about the to-be-reported feature (neutral cue, "X"). After another delay period, a highly salient distractor appeared in the center of the screen followed by another delay interval. The visual distractor was included for facilitating decoding of the cued working memory representations (see Wolff et al., 2017) and therefore is not relevant for the current investigation. Finally, a memory probe, which consisted of a circle with either one marker (location report) or two opposing markers (orientation report) at a randomly chosen position appeared. Upon memory probe presentation, participants had to adjust the marker(s) position to indicate the cued feature (i.e., the grating's location or orientation). Following a neutral feature cue, the type of memory probe (one mark vs. two marks) indicated the target feature. Once the probe was correctly adjusted, each answer had to be confirmed by a button press within $4 \mathrm{~s}$. Otherwise the trial was considered incomplete. The task consisted of 720 trials ( 240 per feature cue condition) and the whole experiment (including the EEG cap preparation) lasted around 3.5 hours.

\subsubsection{Experiment 2}

The second experiment differed from the first one in the sense that participants had to perform one of two possible tasks: either the same location/orientation continuous report task 
as in experiment 1 (50\% of the trials) or a recognition task (50\% of the trials). After memorizing the location and orientation of the grating presented in the memory array, a retrospective feature cue (location cue, orientation cue or neutral feature cue) indicated which feature was going to be relevant at the end of the trial. The delay interval after the feature cue was followed by a second retro-cue indicating whether participants had to adjust the location or orientation of the probe or to compare a presented feature with the cued feature from the memory array. When the continuous report task was cued (one third of the trials; "K", $\mathrm{K}=$ kontinuierlich; i.e., the German word for "continuous"; see figure 1B) the memory probes were identical to the first experiment. When the recognition task was cued (one third of the trials; "V", V = Vergleich; i.e., German for "comparison") the probe displayed just one feature. The probe location was indicated by a filled grey circle presented at a given location on an imaginary circle. Participants had to indicate by pressing the left or right button on the computer mouse (right hand) whether the position of the grey circle matched the initial position of the memory item. In orientation-recognition trials, a grating with a specific orientation was presented in the center of the screen. Again, participants had to indicate with the computer mouse buttons whether this was the same or different orientation as presented in the memory array. The probe matched the memory array in half of the recognition task trials. The assignment of responses to the computer mouse buttons was counterbalanced across participants. In one third of the trials, the task cue was neutral and participants could infer which task they should perform by looking at the probe display. When the probe was a circle with one or two marks on it, they had to perform the continuous report task. When it was either a filled grey circle or a centrally presented grating, the recognition task had to be performed. The combination of feature and task cues resulted in nine conditions $(3 \times 3$ experimental design) with 80 trials each. The experiment consisted of 720 trials in total and took about 4 hours, including the preparation of the EEG cap. 


\subsection{Behavioral Analysis}

\subsubsection{Experiment 1}

Only complete trials (including a button press following location/orientation report) were included in the analyses and two parameters were considered: the angular error (calculated as the difference between the original orientation/location of the grating and the reported value) and the time to mouse movement (i.e., the time required for starting response initiation). For both parameters, conditions were compared against the respective neutral retro-cue condition with a $t$-test separately for each feature. More specifically, trials with a location feature cue were compared to neutral trials with a location probe and orientation feature cue trials were compared to neutral trials with a later orientation probe. Since location and orientation adjustment featured different maximal angular error values (location: $180^{\circ}$; orientation: $90^{\circ}$ ), angular error analysis was done separately for each feature. To keep the behavioral analysis of experiment 1 consistent, also time to mouse movement onset analysis was conducted this way.

\subsubsection{Experiment 2}

Parameters for the analysis of working memory accuracy and response initiation in the continuous report task were the same as in experiment 1: the angular error and time to mouse movement onset. Only complete trials were included in all analyses. For the recognition task, the percentage of correct responses and response times were analyzed. Here, responses were considered from 150 - 4000 ms after memory probe presentation. Trials with responses prior to this interval were not included in the analyses (premature responses). Responses were considered as erroneous when there was a wrong button press or no button press within 150 $4000 \mathrm{~ms}$ (misses). For all parameters (continuous task: angular error, time to mouse movement onset; recognition task: percentage of correct responses, response times) and features (location, orientation), separate repeated-measures analyses of variance (rm- 
ANOVA) were run with the factors feature cue (selective vs. neutral) and task-cue (selective vs. neutral).

\subsection{EEG recording and preprocessing}

EEG data were recorded using a $128 \mathrm{Ag} / \mathrm{AgCl}$ passive electrode cap (Easycap $\mathrm{GmbH}$, Herrsching, Germany) with a 10/20 configuration (Pivik et al., 1993). Data were recorded with a sampling rate of $1000 \mathrm{~Hz}$ and amplified by a NeurOne Tesla AC-amplifier (Bittium Biosignals Ltd, Kuopio, Finland). During data acquisition, an online $250 \mathrm{~Hz}$ low-pass filter was applied and impedances were kept below $20 \mathrm{k} \Omega$. The FCz electrode was chosen as reference and the AFz as ground electrode.

EEG data were analyzed using MATLAB (R2021a) and the EEGLAB toolbox (v.14.1.2, Delorme \& Makeig, 2004). As the first preprocessing step, data were $0.1 \mathrm{~Hz}$ highpass filtered, using an infinite impulse response (IIR) Butterworth filter, implemented in the ERPLAB toolbox Lopez-Calderon \& Luck, 2014) and down-sampled to $500 \mathrm{~Hz}$. Channels containing a high level of artifacts were excluded using the automated channel rejection procedure implemented in EEGLAB (i.e., pop_rejchan, probability threshold $=5 \mathrm{SD}$, max. $\%$ of trials rejected per iteration $=5 \%$ ). On average, 5.58 channels were excluded per participant $(S D=3.40$, range $=1-11)$ in experiment 1. In experiment $2,7.91$ channels per participant were excluded on average $(S D=3.71$, range $=1-17)$.

Next, data were re-referenced to a common average. For the independent component analysis (ICA), data were filtered with a $1 \mathrm{~Hz}$ high-pass and a $40 \mathrm{~Hz}$ low-pass IIR Butterworth filter (pop_basicfilter(); low-pass filter with a cutoff frequency of $1 \mathrm{~Hz}$, high-pass filter with a cutoff frequency of $40 \mathrm{~Hz}$, filter length $=8$ data points) and down sampled to 250 Hz. As a second step, data were separated into epochs time-locked to the memory array (experiment 1: $1000 \mathrm{~ms}$ before and $6000 \mathrm{~ms}$ after the memory array; experiment 2: $1000 \mathrm{~ms}$ before and $7400 \mathrm{~ms}$ after the memory array). Finally, trials containing extreme fluctuations were excluded with an automated artifact rejection procedure (pop_autorej(); threshold $=500$ 
$\mathrm{mV}$, probability threshold $=5 \mathrm{SD}$, max. $\%$ of rejected trials per iteration: $5 \%$ ). On average, 663.33 trials remained for the ICA $(S D=36.95$, range $=591-712)$ in experiment 1 and 670.05 trials $(S D=41.70$, range $=598-718)$ in experiment 2.

ICA was conducted on the rank reduced data (number of channels minus 1) and components reflecting artifacts (eye movements, blinks, generic data discontinuities) were identified using ADJUST (Mognon et al., 2011). Subsequently, ICA decomposition results were transferred to the original $500 \mathrm{~Hz}$ data set. Single-equivalent current dipoles were fitted on the ICs based on a spherical head model using the dipfit-plugin of the EEGLAB toolbox. Based on the dipole solution, ICs with a residual variance exceeding 50\% were excluded. Overall, 49.83 components $(S D=9.21$, range: $35-67)$ were excluded in experiment 1 . In experiment 2, 50.59 components $(S D=12$, range: $28-73)$ were excluded.

Afterwards, epochs time-locked to the memory array-were obtained and the $200 \mathrm{~ms}$ interval prior to memory item onset was used as a baseline. Trials still containing extreme fluctuations were identified and excluded through an automated artifact rejection procedure $($ threshold $=1000$, probability $=5 \mathrm{SD}$, max. $\%$ of trials rejected per iteration $=5 \%)$. On average, 181.88 trials per condition $(S D=17.38$, range $=135-215)($ experiment 1$)$ remained. In experiment $2,60.83(S D=5.86$, range $=41-74)$ trials per condition remained on average. Finally, rejected channels were interpolated based on a spherical head model.

\subsection{Channel-based analysis}

Spectral power was computed by convolving complex Morlet wavelets with each trial of the EEG data. Frequencies between 4 and $30 \mathrm{~Hz}$ were included, which increased in logarithmic steps of 52. The width of the Gaussian, defined by the number of cycles, increased linearly by a factor of 0.5 , resulting in three cycles at the lowest and 11.5 cycles at the highest frequency. An interval of $200 \mathrm{~ms}$ before memory array onset (-200 to 0 ) was used as spectral baseline. The resulting epochs contained 200 time points ranging from $-1000 \mathrm{~ms}$ 
bioRxiv preprint doi: https://doi.org/10.1101/2022.01.25.477681; this version posted January 27,2022 . The copyright holder for this preprint (which was not certified by peer review) is the author/funder, who has granted bioRxiv a license to display the preprint in perpetuity. It is made available under aCC-BY-NC-ND 4.0 International license.

before to $6000 \mathrm{~ms}$ after memory array onset (experiment 2: $-1000 \mathrm{~ms}$ to $7400 \mathrm{~ms}$ after memory array onset).

Similar to Schneider et al. (2017), four clusters of electrodes were chosen to investigate to what extent the retrospective cuing of object features led to a modulation of oscillatory power prior to memory probe presentation: two clusters over the left (PO3, PO7, PPO5h, P7, $\mathrm{P} 5)$ and right (PO4, PO8, PPO6h, P8, P6) parieto-occipital cortex and two clusters over the left (CP3, CCP5h, CCP3h, C3) and right (CP4, CCP6h, CCP4h, C4) sensorimotor cortex. As a first step, data were averaged across these clusters and across the two selective feature cue conditions. A cluster-based permutation procedure was performed in order to find the time window and frequency range in which selective and neutral feature cue conditions differed from each other. Since differences in this regard should appear following the retro-cue (the first retro-cue for experiment 2), only data between the retro-cue and the probe were included in the permutation procedure. Condition labels (selective vs. neutral feature cue) were randomly assigned to each data set. This was repeated 1000 times. A two-sided within subject $t$-test was performed for each time-frequency data point on each iteration resulting in a time points $(68) \mathrm{x}$ frequencies (52) x permutations (1000) matrix (experiment 2: time points (63) x frequencies (52) x permutations (1000)). For each permutation, the size of the largest timefrequency cluster with $p<.05$ was assessed. Differences between selective and neutral feature cues in the original data were considered significant, if the size of time-frequency cluster was larger than the $95^{\text {th }}$ percentile of the distribution of cluster sizes created by the permutation procedure.

Subsequently, a rm-ANOVA with the factors condition (location feature cue vs. orientation feature cue vs. neutral feature cue), hemisphere (left vs. right electrode clusters) and caudality (posterior vs. central electrode clusters) was performed on the identified timefrequency clusters. 


\subsection{Inferential statistics and effect sizes}

When indicated by Mauchly's test for sphericity, Greenhous-Geisser correction was applied (indicated by $\varepsilon$ ). Effect sizes in ANOVAs are indicated by partial eta squared $\left(\eta^{2} p\right)$ and by Cohens $d_{z}$ for within-subject $t$-tests. To prevent $p$-value inflation due to multiple comparisons, the false discovery rate (FDR) procedure (adjusted $p$ values / $p_{\text {adj }}$ are reported in this regard; Benjamini \& Hochberg, 1995) was used for post-hoc comparisons and also to adjust for hidden multiplicity within rm-ANOVAs (Cramer et al., 2016). Additionally, the boundaries of the $95^{\text {th }}$ confidence interval (CI) surrounding the mean condition differences are reported.

\subsection{Independent component clustering}

A clustering procedure on IC level was used to isolate the mu/beta activity over the sensorimotor cortex from posterior alpha activity and to prove the sensorimotor source of the $\mathrm{mu} /$ beta suppression.

All parameters used for the clustering procedure were based on the approach by Schneider et al. (2017). However, the number of clusters resulting from the k-means clustering algorithm was changed to 24 , due to the higher number of channels (resulting in a higher number of ICs). Only ICs with less than $20 \%$ residual variance regarding their dipole solution were included in the clustering procedure (see Schneider et al., 2017). Event-related spectral perturbations (ERSPs) for the individual ICs were calculated with the same parameters as for the channel-based analysis. Frequency spectra were computed using an FFT (fast-Fourier transform) procedure. The clustering was based on dipole solutions (three dimensions), scalp distributions (10 dimensions), ERSPs between 4 and $30 \mathrm{~Hz}(10$ dimensions) and spectral power between 4 and $30 \mathrm{~Hz}$ (10 dimensions). The number of dimensions define to what extent the different features contribute to the generation of the clusters (Onton \& Makeig, 2006). As the IC dipole solution can only contribute three dimensions ( $\mathrm{x}, \mathrm{y}$ and $\mathrm{z}$ values), its relative contribution to clustering was weighted by a factor 
bioRxiv preprint doi: https://doi.org/10.1101/2022.01.25.477681; this version posted January 27,2022 . The copyright holder for this preprint (which was not certified by peer review) is the author/funder, who has granted bioRxiv a license to display the preprint in perpetuity. It is made available under aCC-BY-NC-ND 4.0 International license.

of 10. The clustering algorithm (MATLAB statistics toolbox) separated 890 ICs into 24 clusters (experiment 2: 801 ICs into 24 clusters). An additional cluster was defined for outlier ICs with more than $3 S D$ from any of the cluster centroids.

Based on these criteria, we observed two IC clusters that featured the typical characteristics of the mu and beta oscillatory response in preparation for responses and during their execution in both Experiment 1 and 2. There was one left-hemispheric or contralateral mu/beta cluster (cluster 9 for Experiment 1; cluster 24 for Experiment 2; see supplementary figures A and B) and one right-hemispheric or ipsilateral cluster (cluster 22 for Experiment 1; cluster 15 for Experiment 2). Both clusters featured the typical double-peak in higher alpha and beta frequencies on spectral level (see figures $5 \mathrm{~B}$ and D, 8 B and D). To further illustrate the neural sources of these clusters, we specified the MNI coordinates with the peak dipole density and then expanded this point to a sphere with a radius that had the length of $1 S D$ referred to each dipole coordinate ( $\mathrm{x}, \mathrm{y}$ and $\mathrm{z}$ ). The statistical sources were defined by the number of grid points within this extended spatial sphere that belonged to a specific anatomical structure, divided by the number of all grid points (see figures 5, 7 and 8 ). This procedure was based on the std_dipoleDensity() function of EEGLAB. For statistical analyses, ICs from subjects contributing several ICs to one of the clusters were averaged.

For Experiment 1, ERSP responses generated by the statistical sources from 18 participants (left-hemispheric cluster) and 21 participants (right-hemispheric cluster) were compared between the two selective feature cue conditions (location vs. orientation) and the neutral condition by a cluster-based permutation approach comparable to the one described for the channel-based analysis. For Experiment 2 (left-hemispheric cluster: 21 participants; right-hemispheric cluster: 20 participants), the same cluster-based permutation approach was used for analyzing condition effects based on the first feature retro-cue (location vs. orientation vs. neutral) and the second task cue (continuous report vs. comparison vs. neutral).

\section{Results}




\subsection{Behavioral results}

\subsubsection{Experiment 1}

The angular error (see figure $2 \mathrm{~A}$ ) for location adjustment was lower following a location feature cue than following a neutral feature cue, $t(23)=-2.47, p_{a d j}=.043, d_{z}=-0.50$, CI 95\% [-2.12 -0.19]. This was not the case for orientation adjustment trials, $t(23)=-1.88$, $p_{a d j}=.072, d_{z}=-0.38, \mathrm{CI} 95 \%$ [-1.64 0.08]. Response initiation (indicated by time to mouse movement onset; see figure 2B) was accelarated by the selective feature cue (location adjustment selective vs. neutral cue: $t(23)=-11.48, p_{a d j}<.001, d_{z}=-2.34$, CI $95 \%[-195.83-$ 136.01]; orientation adjustment selective vs. neutral cue: $t(23)=-10.49, p_{\text {adj }}<.001, d_{z}=-$ 2.12, CI 95\% [-149.37-100-16]).

\section{\#\#\#\# insert figure 2 here \#\#\#\#}

\subsubsection{Experiment 2}

For experiment 2, precision of working memory performance (see figure $3 \mathrm{~A}$ ) in the continuous task was reliably increased for location adjustment by a selective feature cue, as revealed by a main effect of feature cue, $F(1,21)=14.26, p_{a d j}=.003, \eta^{2}{ }^{2}=0.40$, while there was no influence of the task cue on probe adjustment, $F(1,21)=0.37, p_{\text {adj }}=.548, \eta^{2}{ }^{2}=0.02$. Orientation adjustment was not affected by any of the cues (feature cue: $F(1,21)=0.04, p_{a d j}=$ $.962, \eta^{2}{ }_{p}<.01$; task cue: $\left.F(1,21)<0.01, p_{a d j}=.962, \eta^{2}{ }_{p}<0.01\right)$.

For the recognition task, the percentage of correct responses (see figure 3B) was used to assess working memory accuracy. Here, selective feature cues increased performance, $F(1,21)$ $=27.46, p_{a d j}<.001, \eta_{p}^{2}=0.57$. As in the continuous task, the task cues had no effect on accuracy, $F(1,21)=0.36, p_{a d j}=.647, \eta^{2}{ }_{p}=0.02$. In general, performance was better for location than for orientation recognition, $F(1,21)=24.97, p_{a d j}<.001, \eta^{2}=0.54$.

As in experiment 1, time to mouse movement onset (see figure 3C) was utilized as a measure for speed of response initiation in the continuous report task. Response initiation for location, as well as for orientation adjustment was fastened by the selective feature cue 
(location adjustment: $F(1,21)=52.79, p_{a d j}<.001, \eta^{2}{ }_{p}=0.72$; orientation adjustment: $F(1,21)$ $\left.=35.62, p<.001, \eta^{2}{ }_{p}=0.63\right)$ and by the selective task cue (location adjustment: $F(1,21)=$ 28.11, $p<.001, \eta^{2} p=0.57$; orientation adjustment: $\left.F(1,21)=27.83, p_{a d j}<.001, \eta^{2}=0.57\right)$. While these factors did not significantly interact in location adjustment trials, $F(1,21)=3.82$, $p_{a d j}=.064, \eta^{2}{ }_{p}=0.15$, the interaction was statistically reliable when orientation had to be reported, $F(1,21)=5.19, p_{a d j}=.033, \eta^{2}{ }_{p}=0.20$. The significant interaction resulted from a stronger effect of a selective task cue on orientation adjustment after a selective feature cue, $t(21)=-4.76, p_{a d j}<.001, d_{z}=-1.02$, CI 95\% [-121.46 -47.63], than after a neutral feature cue, $t(21)=-2.89, p_{a d j}=.009, d_{z}=-0.62$, CI $95 \%[-64.18-10.46]$.

Responses to the recognition task were faster after selectively cueing either of the features, $F(1,21)=36.69, p_{a d j}<.001, \eta^{2} p=0.64$. The selective task cue also decreased response times, $F(1,21)=27.79, p_{a d j}<.001, \eta^{2}{ }_{p}=0.57$. Response times in general were faster for location than for orientation recognition, $F(1,21)=55.17, p_{a d j}<.001, \eta^{2} p=0.72$. Finally, the effect of the feature cue differed between the cued features, $F(1,21)=7.93, p_{a d j}=.010, \eta^{2} p$ $=0.27$, in the way that selective feature cues decreased response times more strongly in location, $t(21)=-5.44, p_{a d j}<.001, d_{z}=-1.16$, CI 95\% [-205.39 -91.84], than orientation recognition trials, $t(21)=-3.77, p_{a d j}=.001, d_{z}=-0.80$, CI 95\% [-103.04 -29.73].

Summarized, also experiment 2 indicated an overall performance benefit of selective feature cues. While the task cues did not consistently affect performance, a benefit was shown regarding response initiation processes in both the continuous report and the recognition task. This is especially true for a continuous report of orientation, since here a selective feature cue further amplified the acceleration of response initiation following a selective task cue.

\section{\#\#\#\# insert figure 3 here \#\#\#\#}

\subsection{EEG results}

\subsubsection{Experiment 1}

Channel-based analysis 
Analyses on EEG level were focused on the left (PO3, PO7, PPO5h, P7, P5) and right (PO4, PO8, PPO6h, P8, P6) posterior electrodes as well as on the left (CP3, CCP5h, CCP3h, C3) and right (CP4, CCP6h, CCP4h, C4) electrodes over sensorimotor sites. In a first step, time-frequency data were collapsed over all electrode clusters and selective and neutral trials were contrasted by a cluster-based permutation procedure, which revealed a broad significant difference in mu and beta frequency ranges following the feature cue (see figure 4A). Based on this time-frequency cluster, a rm-ANOVA was run with the factors condition (location vs. orientation vs. neutral feature cue) x hemisphere (left vs. right) x caudality (central vs. posterior). Importantly, this ANOVA revealed a 3-way interaction, $F(2,46)=3.47, p=.039$, $\eta^{2}{ }_{p}=0.13$ (see figure $\left.4 \mathrm{C}-\mathrm{F}\right)$.

When only considering the posterior recording sites, there was a condition $x$ hemisphere interaction, $F(2,46)=4.59, p=.015, \eta^{2} p=0.13$. The condition effect was stronger over left posterior sites, $F(2,46)=18.48, p_{a d j}<.001, \eta^{2} p=0.45, \varepsilon=.66$, than over right posterior sites, $F(2,46)=9.49, p_{a d j}=.008, \eta^{2} p=0.29, \varepsilon=0.73$. The 3-way interaction can be explained by the fact that for the central recording sites, there was an even stronger condition $x$ hemisphere interaction, $F(2,46)=11.17, p_{a d j}<.008, \eta_{p}^{2}=0.33$. Again, the feature cue effect was stronger over the left hemisphere, $F(2,46)=17.48, p_{a d j}<.001, \eta^{2}{ }_{p}=0.43, \varepsilon=0.78$, than over the right hemisphere, $F(2,46)=6.29, p_{a d j}=.004, \eta^{2}{ }^{2}=0.22, \varepsilon=0.78$.

Summarized, there was a stronger hemispheric difference regarding the feature cue effect (selective vs. neutral) over the sensorimotor cortex than over posterior visual areas. This might indicate that the lateralized mu/beta effect was associated with the planning of the right-handed motor response following selective feature cues. To further support this assumption, we looked specifically at oscillatory power from estimated neural sources in left vs. right sensorimotor cortex based on an IC-clustering approach. 
Dipole density analysis indicated estimated neural sources in the left sensorimotor cortex for IC cluster 18 (located with 36\% probability in the precentral gyrus and 36\% probability in the post central gyrus; see figure 5C) and right sensorimotor cortex for IC cluster 21 (located with $44 \%$ probability in the precentral gyrus and $33 \%$ probability in the middle frontal gyrus; see figure $5 \mathrm{~F})$.

All conditions were contrasted by separate cluster-based permutation procedures. Both the location and the orientation feature cues led to differences in oscillatory power in mu and beta frequency range relative to the neutral cue condition (see figure $5 \mathrm{~A}$ ). Importantly, only for the left (contralateral) IC cluster, this effect appeared clearly prior to the onset of the memory probes demanding the actual motor response. For the right (ipsilateral) IC cluster, the minor differences between the selective and neutral cue conditions were only evident after memory probe presentation (see figure $5 \mathrm{C}$ ).

\section{\#\#\#\# insert figure 5 here \#\#\#\#}

\subsubsection{Experiment 2}

\section{Channel-based analysis}

Oscillatory power averaged over the four electrode clusters was compared between the selective and neutral feature cue conditions and revealed a time-frequency cluster with a significant difference after the feature cue presentation (see figure 6). Like for experiment 1 , the subsequent rm-ANOVA revealed a significant condition $x$ hemisphere $x$ caudality interaction, $F(2,42)=4.36, p=.019, \eta^{2} p=0.17$. While a subsequent ANOVA on posterior channels revealed no hemispheric difference regarding the condition effect, $F(2,42)=0.76$, $p_{a d j}=.477, \eta^{2}{ }_{p}=0.04$, the same analysis focusing on the two central electrode clusters found a significant condition $x$ hemisphere interaction, $F(2,42)=4.44, p=.018 \eta^{2} p=0.17$. This again suggested that the stronger suppression of mu and beta power following selective feature cues was related to motor preparation processes. 


\section{IC-based analysis}

As revealed by the dipole density analysis, the left-hemispheric mu/beta IC cluster 24 (precentral gyrus: 24\%; postcentral gyrus: 43\%) and the right-hemispheric mu/beta IC cluster 15 (precentral gyrus: 44\%; middle frontal gyrus: 33\%) were estimated in sensorimotor and premotor cortex with a high probability. Only for the left-hemispheric mu/beta IC cluster, the cluster-based permutation procedure revealed a stronger suppression of oscillatory power following the location cue than following the neutral cue. Similarly, there was a stronger suppression of oscillatory power after the orientation cue than after the neutral cue. The two selective feature cue conditions revealed no difference in this regard (see figure 7A). This highlights that, even when the to-be-executed task was not yet fully specified, cuing of the target feature resulted in a stronger suppression of mu and beta oscillatory power, but only in the sensorimotor cortex contralateral to the future response.

Comparing the data based on the second task cue (see figure 8) revealed a significant cluster of stronger mu and beta suppression following a continuous report task cue than a neutral task cue. Cuing a recognition task resulted in a stronger suppression of mu oscillatory power compared to a neutral task cue. Interestingly, there was also a difference between the selective task cues. The continuous report task cue resulted in a stronger mu and beta suppression 712-1206 ms after cue onset.

\#\#\#\# insert figure 7 here \#\#\#\#

\#\#\#\# insert figure 8 here \#\#\#\#

\section{Discussion}

By means of oscillatory parameters of the EEG, the present study demonstrates that the selection of visual features stored in working memory results in the concurrent selection of 
preparatory motor codes. This is true even when an individual feature of a single item stored in working memory is selected and when the exact, to-be-executed task is still unknown.

In line with earlier research on feature selection in working memory (Hajonides et al., 2020; Niklaus et al., 2017; Sasin \& Fougnie, 2020; Ye et al., 2016), we could show in Experiment 1 that a retrospective cue towards only a single feature of a visual object caused a performance benefit relative to a neutral cue condition, both in terms of working memory precision and the speed of response initiation (see figure 2). On the electrophysiological level, we observed a suppression of alpha (or $\mathrm{mu})$ and beta power $(\sim 8-30 \mathrm{~Hz})$ at posterior and centro-parietal recording sites that was stronger following selective feature cues (see figure 4). Importantly, and in line with a prior investigation from our lab (see Schneider et al., 2017), the centro-parietal electrode clusters featured an increased hemispheric difference, with a stronger suppression of oscillatory power over the left-hemispheric electrodes. In addition to the suppression of posterior alpha power already shown in the context of feature selection in working memory (Hajonides et al., 2020), this indicates an oscillatory effect prior to memory probe presentation that appeared specifically over the motor cortex contralateral to the responding hand. Earlier research has shown that this contralateral suppression of oscillatory power appeared prior to both left-sided and right-sided motor responses (Schneider et al., 2020; van Ede et al., 2019; Zickerick et al., 2021).

The IC-clustering approach supported the contralateral mu and beta suppression effect (see figures 5B). We obtained both a left-hemispheric and right-hemispheric IC cluster with the typical spectral peaks in mu and beta frequencies and estimated neural sources in sensorimotor and pre-motor cortex. Importantly, only the left-hemispheric cluster (i.e., the cluster contralateral to the executed motor response) featured a stronger suppression of mu and beta power following the selective feature cues. The ipsilateral mu/beta IC cluster showed differences in oscillatory power only after memory probe presentation (see figure 5E). This oscillatory pattern has typically been linked to the planning of a response prior to its actual 
execution, both when selecting information relevant for later action from working memory (e.g. Boettcher et al., 2021, S. 2; Schneider et al., 2017, 2020; van Ede, 2018) and prior to self-paced movements (Leocani et al., 1997; Pfurtscheller et al., 2000; Zhuang et al., 1997). Thus, whereas the posterior suppression of alpha power can be associated with the selection of a visuospatial representation stored in working memory, the suppression in mu and beta frequencies over contralateral centro-parietal areas can be linked to the concurrent selection of a motor code associated with the cued visual feature. The stronger suppression of mu and beta power following the selective retro-cues appeared both when location and when orientation was the relevant feature. This clearly shows that such motor-related processing is not specific to the selection of individual items from working memory (Boettcher et al., 2021; Schneider et al., 2017; van Ede et al., 2019). It can thus be assumed that when a task requires the reproduction of individual features of a visual object, associated motor representations can be stored for each feature and selected in preparation for the subsequent motor task.

The second experiment focused on the question whether the precise definition of the upcoming task is a prerequisite for the development of a motor representation in working memory. Olivers and Roelfsema (2020) proposed that the difference between attended and non-attended information stored in working memory might be the coupling of a sensory representation with an action plan. However, it remains unclear whether this coupling requires the precise knowledge of the action to be executed next or whether it also happens when the to-be-executed action is still uncertain. In the latter case, a prospective motor code would be created for dealing with the continuous report task (see experiment 1), even though it would not be necessary for the visual comparison of the memory probe with the stored information (recognition task).

The current study strongly speaks in favor of this latter assumption. Analogous to experiment 1 , the channel-based analysis revealed a stronger suppression of mu and beta power at posterior and centro-parietal sensors following the selective cuing of the location or 
orientation of the stored visual object (i.e., following the first retro-cue). This effect was stronger at electrodes contralateral to the side of the to-be-executed actions, but only for the centro-parietal electrode clusters over left and right sensorimotor cortex (see figure 6).

Moreover, the IC clustering approach strengthened our assumption that this oscillatory effect was linked to motor-related processes and not simply related to feature selection effects reflected in oscillatory patterns in more posterior brain regions. Again, the left-hemispheric (contralateral) and right-hemispheric (ipsilateral) IC cluster featured the typical double spectral peaks in mu and beta frequency ranges and showed the highest estimated dipole density in sensorimotor and pre-motor cortex. Comparable to experiment 1 , only the contralateral cluster revealed a stronger suppression of mu and beta power following the selective feature cues. Thus, experiment 2 shows that a motor-related code was selected at a time when it was not yet clear whether it would be required for the next action to be performed.

In line with these findings, Henderson, Rademaker and Serences (2021) proposed that information stored in working memory can be represented in a rather flexible format, based on the requirements of the task at hand. For example, when it is required to compare the representation of a visual stimulus to a memory probe, the stored mental representation might be based on a "retrospective" visual code. On the other hand, when the information stored in working memory is used to precisely manipulate an object by means of a goal-directed movement, a prospective motor code might additionally be required. This is in line with the pattern of oscillatory activity following the task cues. The contralateral mu/beta IC cluster featured a stronger suppression of oscillatory power following a selective task cue than following a neutral cue (i.e., no task definition until memory probe presentation). This pattern, however, differed between the different task cues. Following the continuous report task cue, we observed a stronger suppression of both mu and beta frequencies (see figure 8A), whereas, this modulation of oscillatory power was limited to the mu frequency range following the 
recognition task cue. Further, when comparing these two conditions directly, the contralateral IC cluster revealed a stronger suppression of mu and beta oscillatory power prior to a cued continuous report task. This suggests that subjects potentially relied more strongly on a prospective motor code when preparing for the continuous report task. Alternatively, subjects might have been preparing for two different tasks in terms of the mere motor requirements. While the continuous report task required an arm movement (in order to move the computer mouse), the recognition task required simply a key press (i.e., a finger movement). Based on the current experiment, we cannot distinguish between these two alternative explanations. To allow for a more specific conclusion in this regard, the two tasks need to be linked to identical motor responses. Nonetheless, the present data clearly show that compared to the neutral condition, both selective cues brought about a further specification of the mental representation of the to-be-executed task.

In summary, the current study sheds light on the role of motor representations for the goal-oriented processing of information in working memory. The first experiment showed that also the retrospective selection of object features can entail the selection of corresponding motor representations. This shows that individual features of a visual object can also be stored and selected as a visual (input) and motor (output) code. The second experiment further highlighted that such motor codes are prospectively generated even when the exact task to be performed is not fully specified. Thus, it can be assumed that the observed effects in the mu and beta frequency range reflect a higher-level representational state of the stored working memory content that serves as a basis for later response planning processes once the to-beexecuted task was cued. This shows that working memory flexibly stores different kinds of memory representations in such a way that the best possible conditions for the execution of a given task are provided.

\section{Acknowledgements}

We would like to thank Tobias Blanke for programming the experiment. 


\section{Conflict of interest statement}

The authors declare that financial and non-financial conflicts of interest do not exist.

\section{References}

Bays, P. M., \& Taylor, R. (2018). A neural model of retrospective attention in visual working memory. Cognitive Psychology, 100, 43-52. https://doi.org/10.1016/j.cogpsych.2017.12.001

Behmer, L. P., \& Fournier, L. R. (2014). Working memory modulates neural efficiency over motor components during a novel action planning task: An EEG study. Behavioural Brain Research, 260, 1-7. https://doi.org/10.1016/j.bbr.2013.11.031

Benjamini, Y., \& Hochberg, Y. (1995). Controlling the False Discovery Rate: A Practical and Powerful Approach to Multiple Testing. Journal of the Royal Statistical Society. Series B (Methodological), 57(1), 289-300.

Boettcher, S. E. P., Gresch, D., Nobre, A. C., \& van Ede, F. (2021). Output planning at the input stage in visual working memory. Science Advances, 7(13), eabe8212. https://doi.org/10.1126/sciadv.abe8212

Cramer, A. O. J., van Ravenzwaaij, D., Matzke, D., Steingroever, H., Wetzels, R., Grasman, R. P. P. P., Waldorp, L. J., \& Wagenmakers, E.-J. (2016). Hidden multiplicity in exploratory multiway ANOVA: Prevalence and remedies. Psychonomic Bulletin \& Review, 23(2), 640-647. https://doi.org/10.3758/s13423-015-0913-5

Delorme, A., \& Makeig, S. (2004). EEGLAB: an open source toolbox for analysis of singletrial EEG dynamics including independent component analysis. Journal of Neuroscience Methods, 134(1), 9-21. https://doi.org/10.1016/j.jneumeth.2003.10.009

Foxe, J. J., \& Snyder, A. C. (2011). The Role of Alpha-Band Brain Oscillations as a Sensory Suppression Mechanism during Selective Attention. Frontiers in Psychology, 2. https://doi.org/10.3389/fpsyg.2011.00154 
bioRxiv preprint doi: https://doi.org/10.1101/2022.01.25.477681; this version posted January 27,2022 . The copyright holder for this preprint (which was not certified by peer review) is the author/funder, who has granted bioRxiv a license to display the preprint in perpetuity. It is made available under aCC-BY-NC-ND 4.0 International license.

Gallivan, J. P., Logan, L., Wolpert, D. M., \& Flanagan, J. R. (2016). Parallel specification of competing sensorimotor control policies for alternative action options. Nature Neuroscience, 19(2), 320-326. https://doi.org/10.1038/nn.4214

Hajonides, J. E., van Ede, F., Stokes, M. G., \& Nobre, A. C. (2020). Comparing the prioritization of items and feature-dimensions in visual working memory. Journal of Vision, 20(8), 25. https://doi.org/10.1167/jov.20.8.25

Händel, B. F., Haarmeier, T., \& Jensen, O. (2011). Alpha Oscillations Correlate with the Successful Inhibition of Unattended Stimuli. Journal of Cognitive Neuroscience, 23(9), 2494-2502. https://doi.org/10.1162/jocn.2010.21557

Henderson, M., Rademaker, R. L., \& Serences, J. T. (2021). Flexible utilization of spatialand motor-based codes for the storage of visuo-spatial information [Preprint]. Neuroscience. https://doi.org/10.1101/2021.07.08.451663

Leocani, L., Toro, C., Manganotti, P., Zhuang, P., \& Hallett, M. (1997). Event-related coherence and event-related desynchronization/synchronization in the $10 \mathrm{~Hz}$ and 20 Hz EEG during self-paced movements. Electroencephalography and Clinical Neurophysiology/Evoked Potentials Section, 104(3), 199-206. https://doi.org/10.1016/S0168-5597(96)96051-7

Lopez-Calderon, J., \& Luck, S. J. (2014). ERPLAB: an open-source toolbox for the analysis of event-related potentials . In Frontiers in Human Neuroscience (Bd. 8, S. 213).

Makovski, T., Sussman, R., \& Jiang, Y. V. (2008). Orienting attention in visual working memory reduces interference from memory probes. Journal of Experimental Psychology: Learning, Memory, and Cognition, 34(2), 369-380. https://doi.org/10.1037/0278-7393.34.2.369

Matsukura, M., Luck, S. J., \& Vecera, S. P. (2007). Attention effects during visual short-term memory maintenance: Protection or prioritization? Perception \& Psychophysics, 69(8), 1422-1434. https://doi.org/10.3758/BF03192957 
bioRxiv preprint doi: https://doi.org/10.1101/2022.01.25.477681; this version posted January 27,2022 . The copyright holder for this preprint (which was not certified by peer review) is the author/funder, who has granted bioRxiv a license to display the preprint in perpetuity. It is made available under aCC-BY-NC-ND 4.0 International license.

Mognon, A., Jovicich, J., Bruzzone, L., \& Buiatti, M. (2011). ADJUST: An automatic EEG artifact detector based on the joint use of spatial and temporal features. Psychophysiology, 48(2), 229-240. https://doi.org/10.1111/j.1469-8986.2010.01061.x

Myers, N. E., Walther, L., Wallis, G., Stokes, M. G., \& Nobre, A. C. (2015). Temporal Dynamics of Attention during Encoding versus Maintenance of Working Memory: Complementary Views from Event-related Potentials and Alpha-band Oscillations. Journal of Cognitive Neuroscience, 27(3), 492-508. https://doi.org/10.1162/jocn_a_00727

Niklaus, M., Nobre, A. C., \& van Ede, F. (2017). Feature-based attentional weighting and spreading in visual working memory. Scientific Reports, 7(1). https://doi.org/10.1038/srep42384

Nobre, A. C., \& Stokes, M. G. (2019). Premembering Experience: A Hierarchy of TimeScales for Proactive Attention. Neuron, 104(1), 132-146. https://doi.org/10.1016/j.neuron.2019.08.030

Oldfield, R. C. (1971). The assessment and analysis of handedness: The Edinburgh inventory. Neuropsychologia, 9(1), 97-113. https://doi.org/10.1016/0028-3932(71)90067-4

Olivers, C. N. L., \& Roelfsema, P. R. (2020). Attention for action in visual working memory. Cortex, 131, 179-194. https://doi.org/10.1016/j.cortex.2020.07.011

Onton, J., \& Makeig, S. (2006). Information-based modeling of event-related brain dynamics. In Progress in Brain Research (Bd. 159, S. 99-120). Elsevier. https://doi.org/10.1016/S0079-6123(06)59007-7

Pashler, H. (1994). Dual-task interference in simple tasks: Data and theory. Psychological Bulletin, 116(2), 220-244. https://doi.org/10.1037//0033-2909.116.2.220

Pertzov, Y., Bays, P. M., Joseph, S., \& Husain, M. (2013). Rapid forgetting prevented by retrospective attention cues. Journal of Experimental Psychology: Human Perception and Performance, 39(5), 1224-1231. https://doi.org/10.1037/a0030947 
bioRxiv preprint doi: https://doi.org/10.1101/2022.01.25.477681; this version posted January 27,2022 . The copyright holder for this preprint (which was not certified by peer review) is the author/funder, who has granted bioRxiv a license to display the preprint in perpetuity. It is made available under aCC-BY-NC-ND 4.0 International license.

Pfurtscheller, G., Neuper, C., \& Krausz, G. (2000). Functional dissociation of lower and upper frequency mu rhythms in relation to voluntary limb movement. Clinical Neurophysiology, 111(10), 1873-1879. https://doi.org/10.1016/S13882457(00)00428-4

Pivik, R. T., Broughton, R. J., Coppola, R., Davidson, R. J., Fox, N., \& Nuwer, M. R. (1993). Guidelines for the recording and quantitative analysis of electroencephalographic activity in research contexts. Psychophysiology, 30(6), 547-558. https://doi.org/10.1111/j.1469-8986.1993.tb02081.x

Sasin, E., \& Fougnie, D. (2020). Memory-driven capture occurs for individual features of an object. Scientific Reports, 10(1), 19499. https://doi.org/10.1038/s41598-020-76431-5

Sauseng, P., Klimesch, W., Stadler, W., Schabus, M., Doppelmayr, M., Hanslmayr, S., Gruber, W. R., \& Birbaumer, N. (2005). A shift of visual spatial attention is selectively associated with human EEG alpha activity. European Journal of Neuroscience, 22(11), 2917-2926. https://doi.org/10.1111/j.1460-9568.2005.04482.x

Schneider, D., Barth, A., \& Wascher, E. (2017). On the contribution of motor planning to the retroactive cuing benefit in working memory: Evidence by mu and beta oscillatory activity in the EEG. NeuroImage, 162, 73-85. https://doi.org/10.1016/j.neuroimage.2017.08.057

Schneider, D., Mertes, C., \& Wascher, E. (2016). The time course of visuo-spatial working memory updating revealed by a retro-cuing paradigm. Scientific Reports, 6(1), 21442. https://doi.org/10.1038/srep21442

Schneider, D., Zickerick, B., Thönes, S., \& Wascher, E. (2020). Encoding, storage, and response preparation-Distinct EEG correlates of stimulus and action representations in working memory. Psychophysiology, 57(6). https://doi.org/10.1111/psyp.13577 
bioRxiv preprint doi: https://doi.org/10.1101/2022.01.25.477681; this version posted January 27,2022 . The copyright holder for this preprint (which was not certified by peer review) is the author/funder, who has granted bioRxiv a license to display the preprint in perpetuity. It is made available under aCC-BY-NC-ND 4.0 International license.

van Ede, F. (2018). Mnemonic and attentional roles for states of attenuated alpha oscillations in perceptual working memory: A review. European Journal of Neuroscience, 48(7), 2509-2515. https://doi.org/10.1111/ejn.13759

van Ede, F., Chekroud, S. R., Stokes, M. G., \& Nobre, A. C. (2019). Concurrent visual and motor selection during visual working memory guided action. Nature Neuroscience, 22(3), 477-483. https://doi.org/10.1038/s41593-018-0335-6

Wolff, M. J., Jochim, J., Akyürek, E. G., \& Stokes, M. G. (2017). Dynamic hidden states underlying working-memory-guided behavior. Nature Neuroscience, 20(6), 864-871. https://doi.org/10.1038/nn.4546

Ye, C., Hu, Z., Ristaniemi, T., Gendron, M., \& Liu, Q. (2016). Retro-dimension-cue benefit in visual working memory. Scientific Reports, 6(1), 35573. https://doi.org/10.1038/srep35573

Zhuang, P., Toro, C., Grafman, J., Manganotti, P., Leocani, L., \& Hallett, M. (1997). Eventrelated desynchronization (ERD) in the alpha frequency during development of implicit and explicit learning. Electroencephalography and Clinical Neurophysiology, 102(4), 374-381. https://doi.org/10.1016/S0013-4694(96)96030-7

Zickerick, B., Kobald, S. O., Thönes, S., Küper, K., Wascher, E., \& Schneider, D. (2021). Don't stop me now: Hampered retrieval of action plans following interruptions. Psychophysiology, 58(2). https://doi.org/10.1111/psyp.13725

Zickerick, B., Thönes, S., Kobald, S. O., Wascher, E., Schneider, D., \& Küper, K. (2020). Differential Effects of Interruptions and Distractions on Working Memory Processes in an ERP Study. Frontiers in Human Neuroscience, 14, 84.

https://doi.org/10.3389/fnhum.2020.00084 
Figure 1
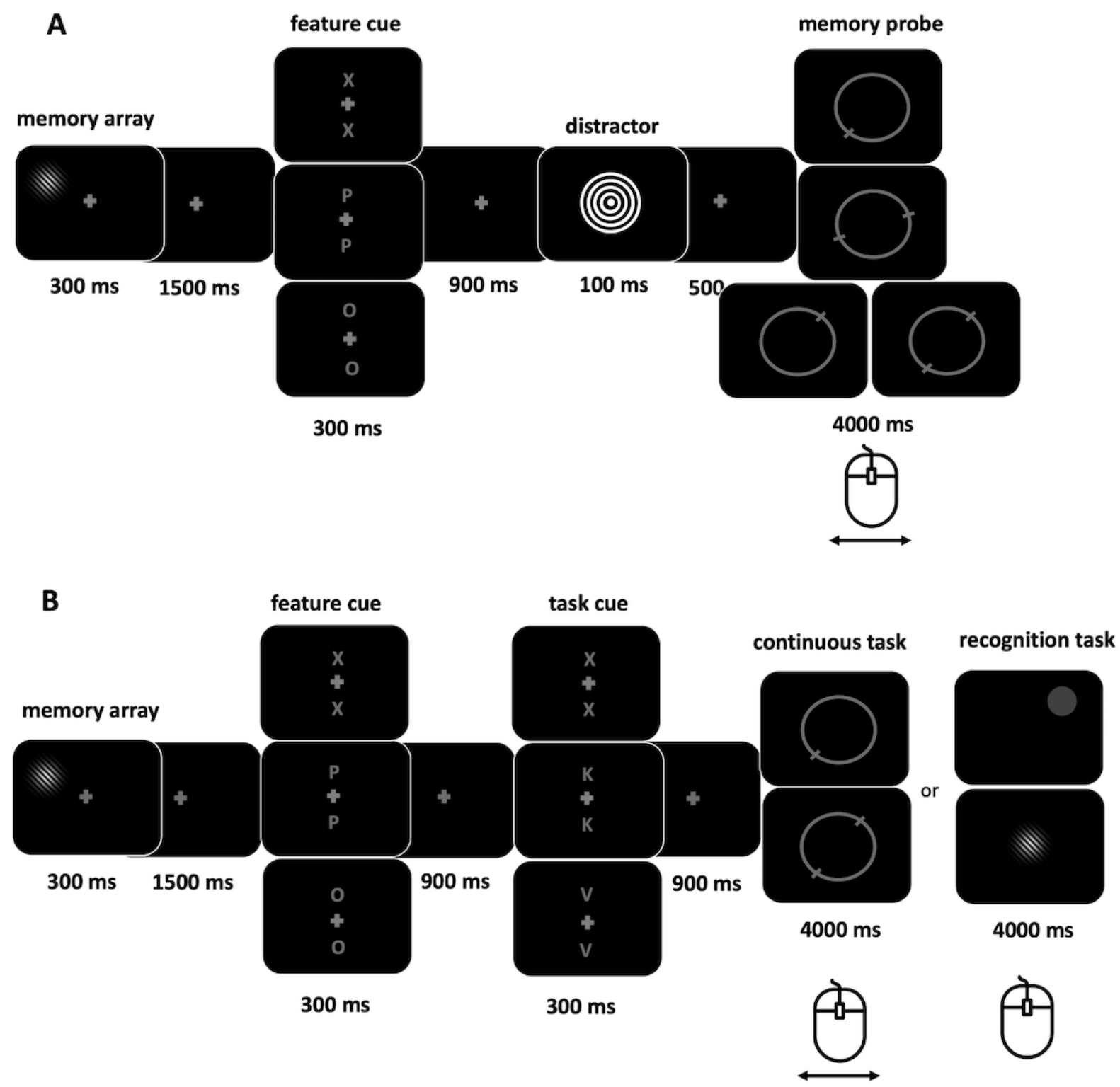

Figure 1. Experimental design. Panel A depicts the procedure of experiment 1. Each trial began with the presentation of an oriented Gabor grating whose location and orientation had to be memorized. After a delay interval, a selective feature cue $(P=$ position, $O=$ orientation, $X=$ neutral) indicated whether participants had to reproduce the orientation or location. Finally, after presentation of a visual distractor stimulus, a memory probe had to be adjusted so that it matched the target feature. The design of experiment 2 is depicted in panel B. Here, the feature cue was followed by a task cue ( $X=$ neutral, $K=$ continuous report task, $V=$ recognition task) indicating whether a continuous report task (as in experiment 1) or a recognition task had to be performed. In the recognition task, either a probe location or a probe orientation was presented and 
bioRxiv preprint doi: https://doi.org/10.1101/2022.01.25.477681; this version posted January $27,2022$. The copyright holder for this preprint (which was not certified by peer review) is the author/funder, who has granted bioRxiv a license to display the preprint in perpetuity. It is made available under aCC-BY-NC-ND 4.0 International license.

participants indicated by mouse click whether it matched the target information from the memory array.

\section{Figure 2}
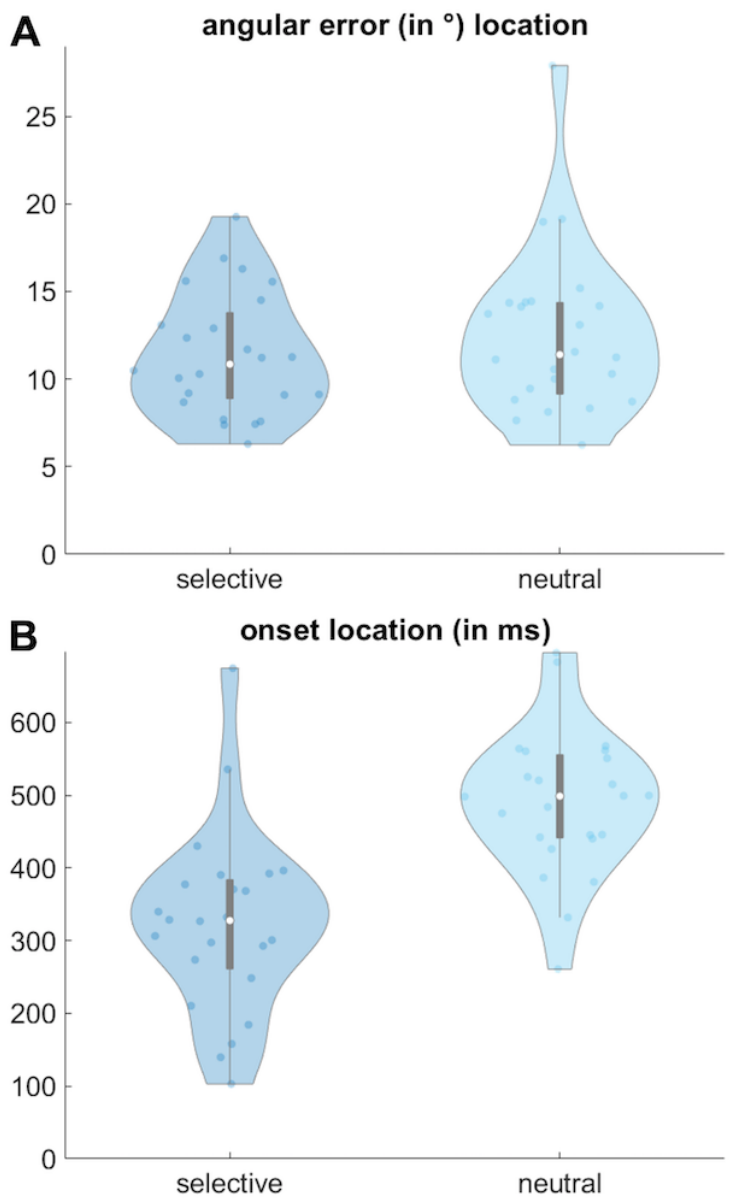

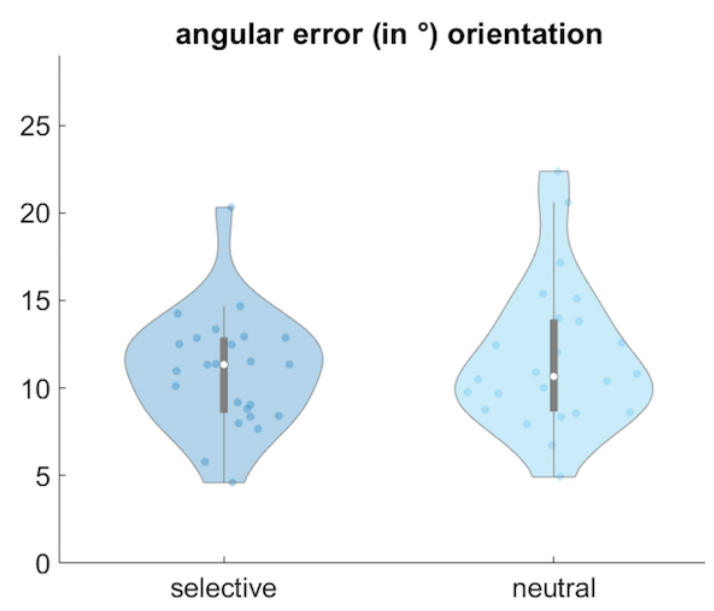

onset orientation (in ms)

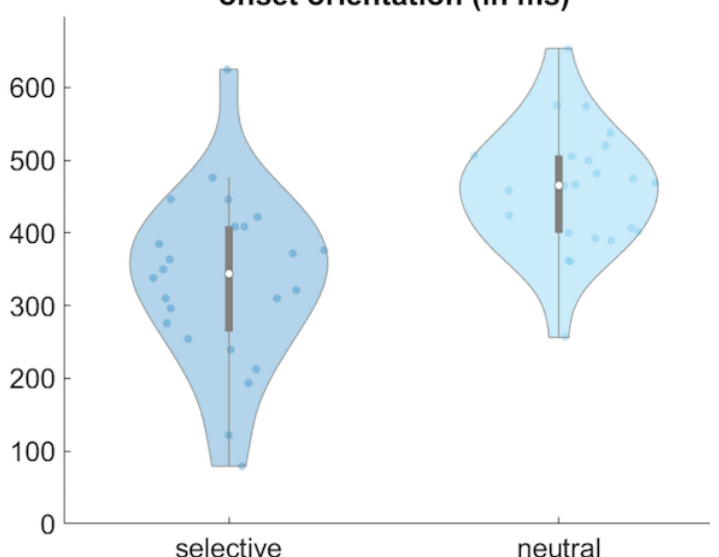

Figure 2. Behavioral result of experiment 1. Panel A shows the angular error for location

feature cues vs. neutral cue conditions (left) and for the orientation feature cue vs. neutral cue conditions (right). The colored dots depict the mean angular error of each participant and the white dot shows the median of each condition. The thick grey line marks the third and fourth quartile, while the thin grey lines mark the upper and lower adjacent. Panel B represents comparisons of the time to mouse movement onset between the above-mentioned conditions. 
bioRxiv preprint doi: https://doi.org/10.1101/2022.01.25.477681; this version posted January 27,2022 . The copyright holder for this preprint (which was not certified by peer review) is the author/funder, who has granted bioRxiv a license to display the preprint in perpetuity. It is made available under aCC-BY-NC-ND 4.0 International license.

Figure 3
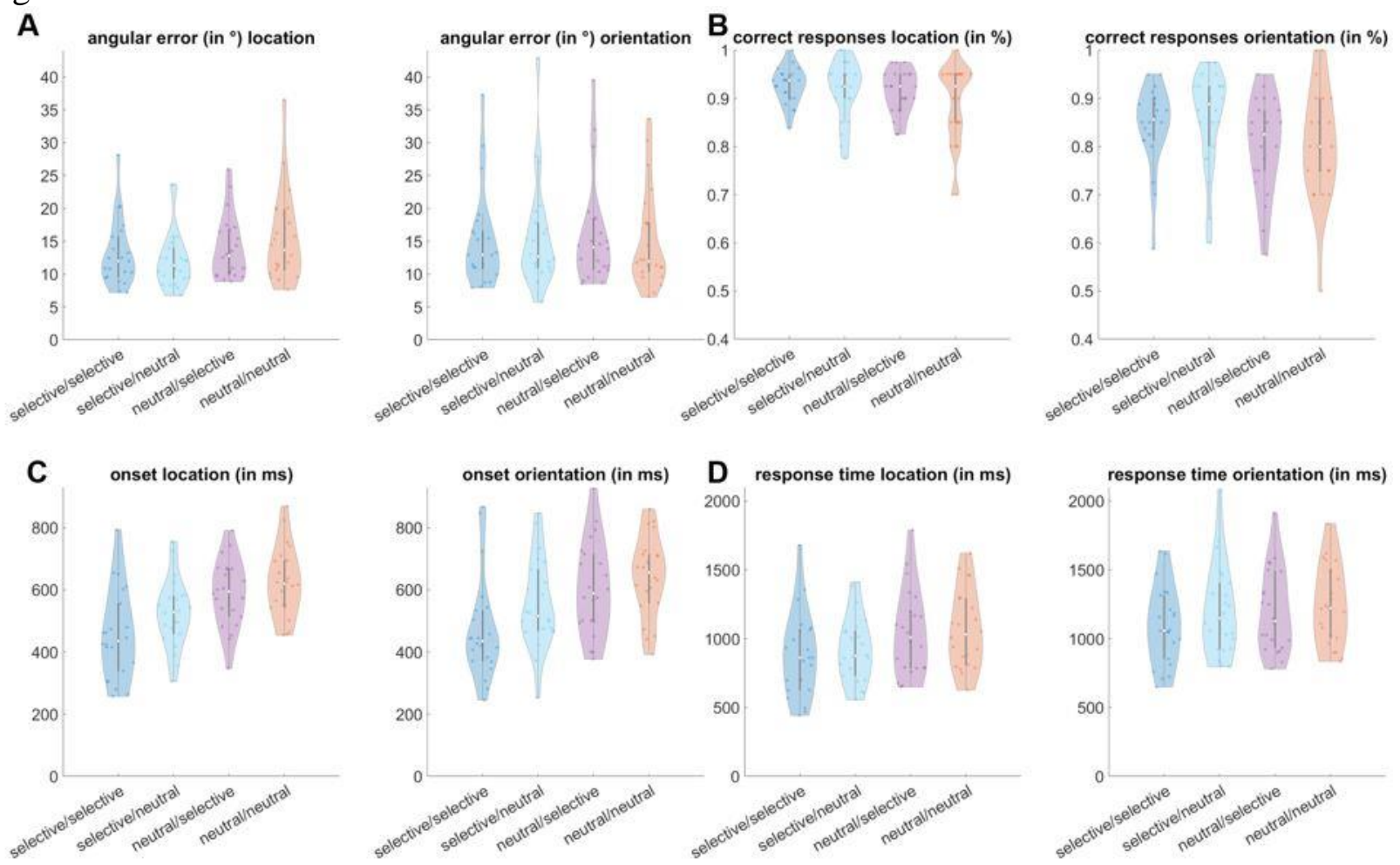

Figure 3. Behavioral result of experiment 2. Panel A shows the angular error for the different combinations of the feature cue (selective vs. neutral) and task-cue (selective vs. neutral). The colored dots depict the mean angular error of each participant, the white dot shows the median of each condition. The thick grey line marks the third and fourth quartile, while the thin grey lines mark the upper and lower adjacent. Panel B represents the percentage of correct responses in the recognition task. Panel C shows the time to mouse movement onset in the continuous report and Panel D the response times in the recognition task. 
bioRxiv preprint doi: https://doi.org/10.1101/2022.01.25.477681; this version posted January $27,2022$. The copyright holder for this preprint (which was not certified by peer review) is the author/funder, who has granted bioRxiv a license to display the preprint in perpetuity. It is made available under aCC-BY-NC-ND 4.0 International license.

Figure 4

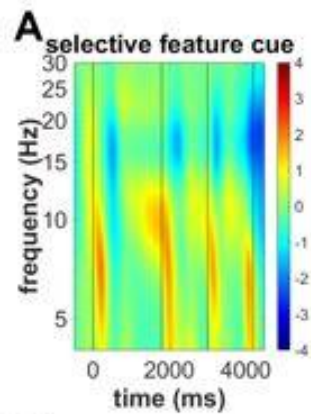

C

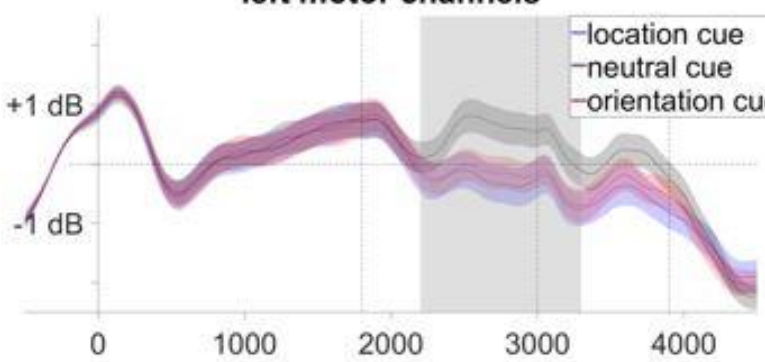

E

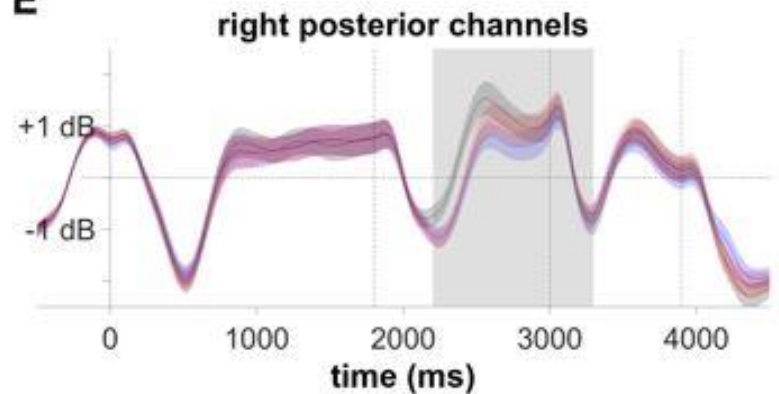

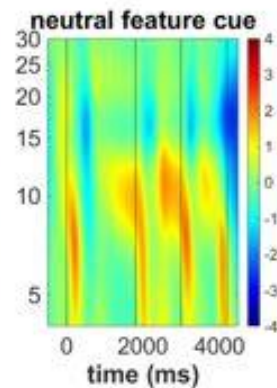

nels
B

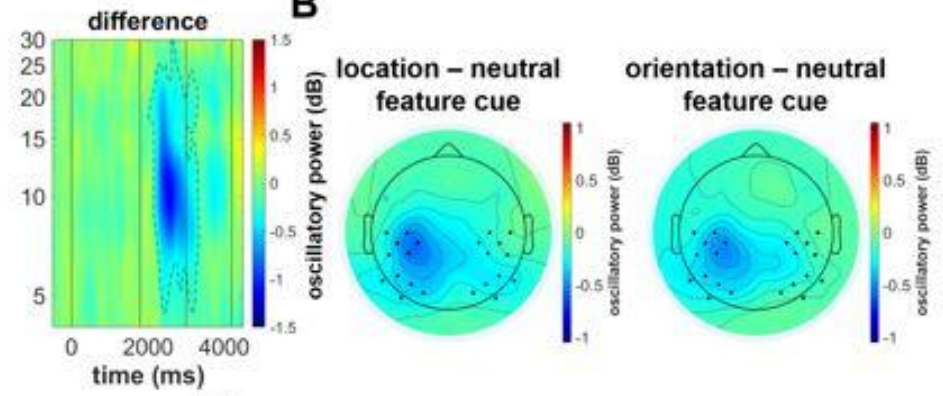

D

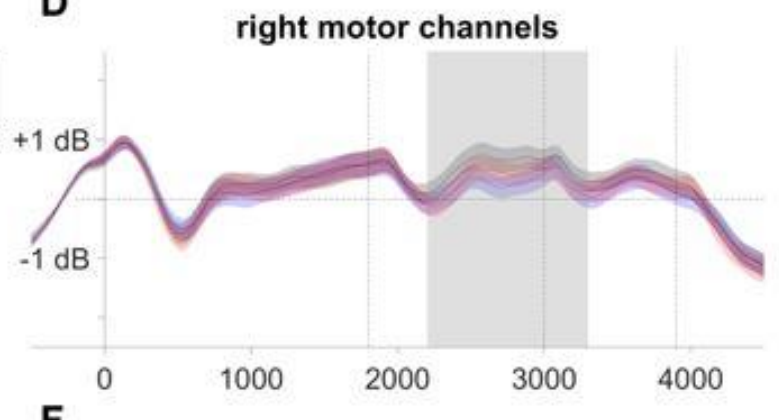

$\mathbf{F}$

left posterior channels

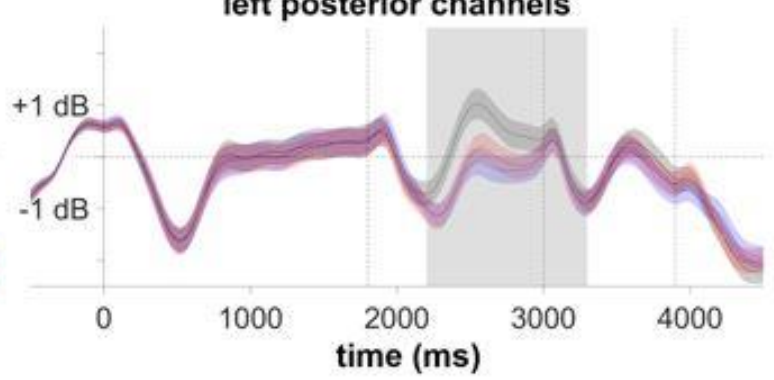

Figure 4. Results of the channel-based analyses. Panel A shows the time-frequency distribution of the activity averaged across channels and subjects for the selective cue, the neutral cue condition, and the difference activity. The vertical solid lines indicate relevant events throughout the trial $(0 \mathrm{~ms}$ memory array onset, 1800 ms - selective cue onset, 3000 ms - 3600 ms visual distractor onset, 3900 ms-memory probe onset). Panel B illustrates the topographical distribution of the location-minusneutral condition activity (left) and the orientation-minus-neutral condition activity (right) averaged across the significant cluster (see dashed line in panel A). Panel C-F highlights the time course of oscillatory power from 2200 to $3300 \mathrm{~Hz}$ for the four electrode clusters of interest. The standard error of the mean is indicated by shaded areas surrounding the condition average. The grey areas depict significant time windows obtained by conducting the cluster-based permutation analysis (see panel A). 
bioRxiv preprint doi: https://doi.org/10.1101/2022.01.25.477681; this version posted January 27,2022 . The copyright holder for this preprint (which was not certified by peer review) is the author/funder, who has granted bioRxiv a license to display the preprint in perpetuity. It is made available under aCC-BY-NC-ND 4.0 International license.

Figure 5
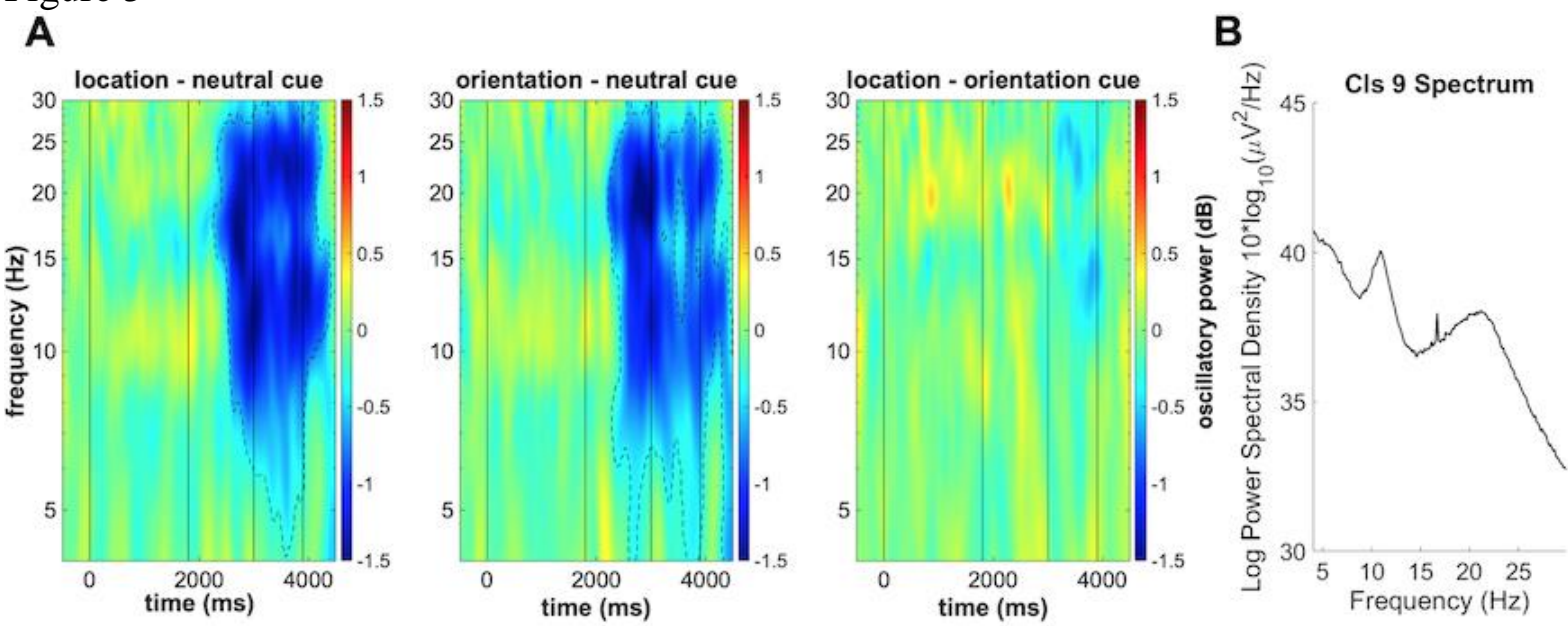

C
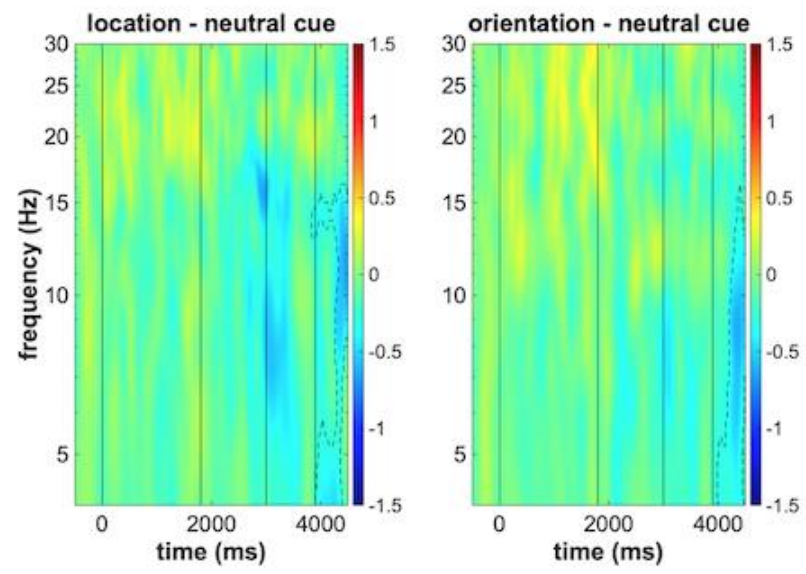

$E$

scalp map Cl9:

33 ICs from 18 subjects

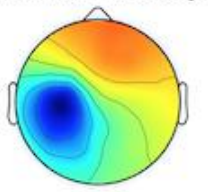

G Cluster dipole densities:

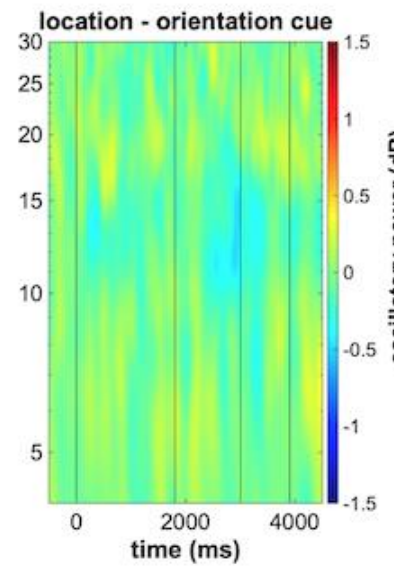

D

$\mathbf{F}$

scalp map $\mathrm{Cl} 22$ :

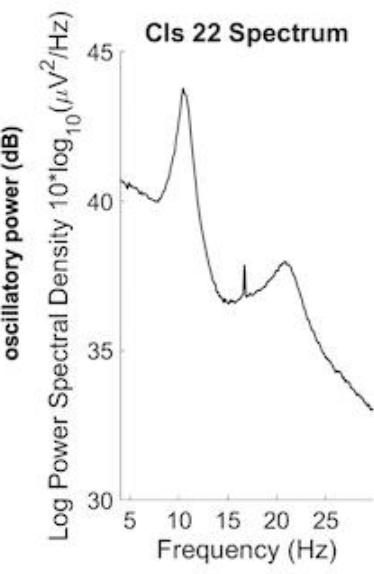

$45 \mathrm{ICs}$ from 21 subjects

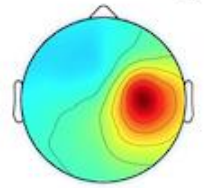

H Cluster dipole densities:

MNI coordinates $-38-248$

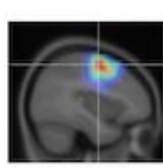

axial

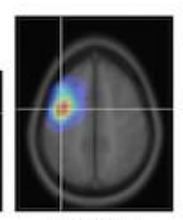

sagittal

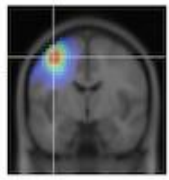

coronal

Postcentral Gyrus: 0.36 (probability)

Precentral Gyrus: 0.36

Middle frontal Gyrus: 0.21

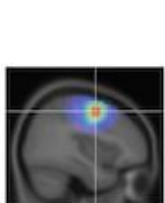

axial

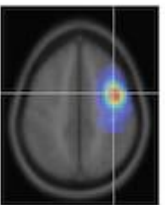

sagittal

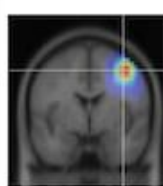

coronal

Precentral gyrus: 44 (probability)

Middle frontal gyrus: 0.33

Brodmann area 6: 0.33

Figure 5. Feature cue effects for contralateral vs. ipsilateral mu/beta IC clusters (experiment

1). Panel A depicts a time-frequency plot showing the condition differences contralateral to the responding hand. Time-frequency clusters differing between the conditions are indicated by a dotted (-

-) line. Panel B shows the spectral power of the left hemispheric IC cluster. Panel C and D are

depicting the respective results for the right hemispheric IC cluster. Panel E and G show the scalp 
bioRxiv preprint doi: https://doi.org/10.1101/2022.01.25.477681; this version posted January 27,2022 . The copyright holder for this preprint (which was not certified by peer review) is the author/funder, who has granted bioRxiv a license to display the preprint in perpetuity. It is made available under aCC-BY-NC-ND 4.0 International license.

map and the respective dipole density distribution of the left hemispheric IC cluster. Panel $F$ and $H$ depict the scalp map and dipole density distribution for the right hemispheric IC cluster.

Figure 6
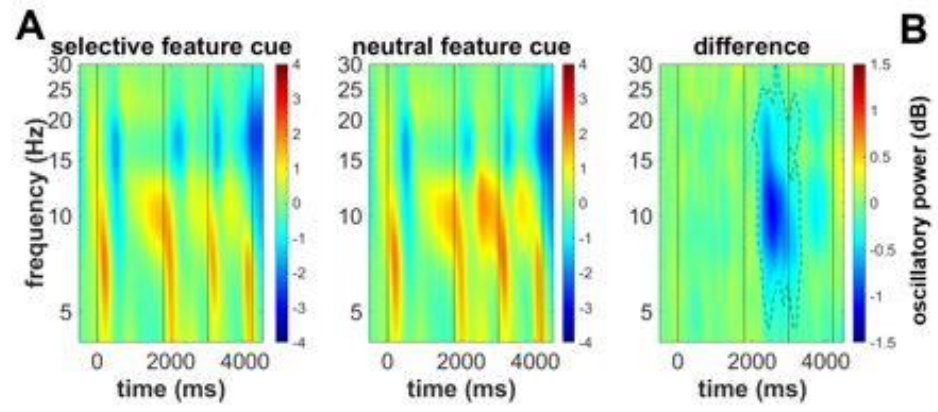

B

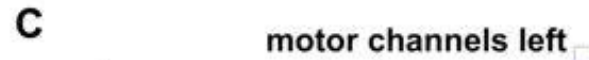

D

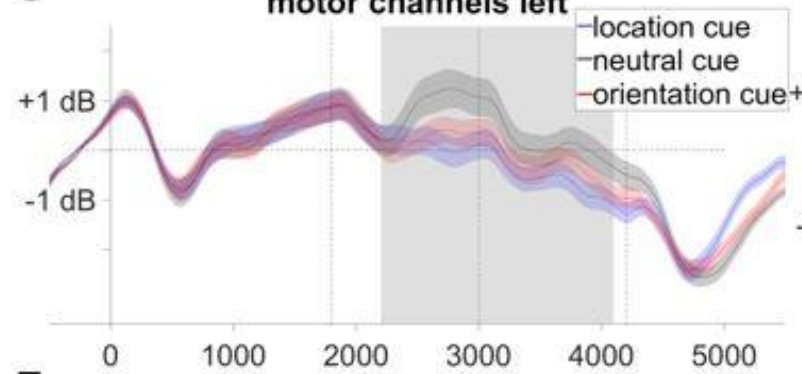

E
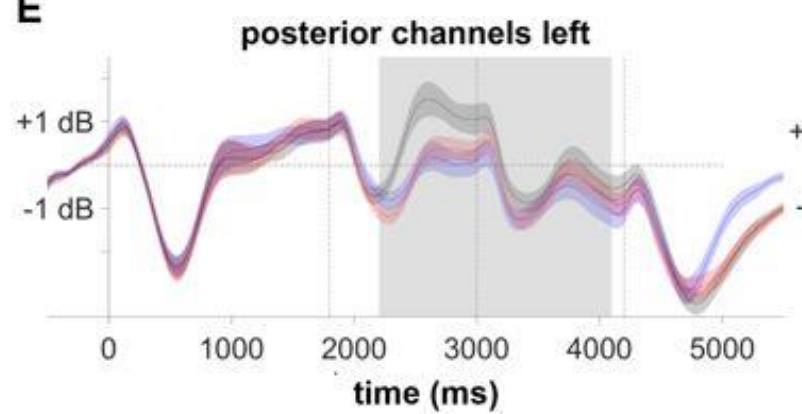

$$
\text { F }
$$

Dotor channels right

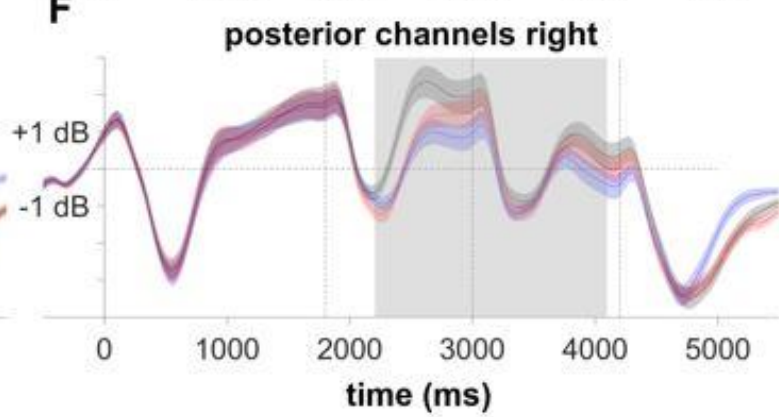

Figure 6. Results of the channel-based analyses (experiment 2). Panel A shows the time-

frequency distribution of the activity averaged across channels and subjects for the selective cue, neutral cue condition, and the difference between the two conditions. The vertical solid lines indicate relevant events throughout the trial (0 ms-memory array onset, $1800 \mathrm{~ms}$ - selective cue onset, $3000 \mathrm{~ms}$ - task cue onset, 3900 ms- 4200 memory probe onset) and the dotted line (--) marks the cluster in which the conditions differ significantly. Panel B illustrates the topographical distribution of the location-minus-neutral condition activity (left) and the orientation-minus-neutral condition activity (right averaged across the significant cluster (see panel A)). Panel C-F highlights the time course of the significant frequency range for the four electrode clusters of interest. The standard error of the mean is indicated by the shaded area surrounding each condition average. The grey areas depict 
bioRxiv preprint doi: https://doi.org/10.1101/2022.01.25.477681; this version posted January 27,2022 . The copyright holder for this preprint (which was not certified by peer review) is the author/funder, who has granted bioRxiv a license to display the preprint in perpetuity. It is made available under aCC-BY-NC-ND 4.0 International license.

significant time windows (2200 ms - $4100 \mathrm{~ms}$ ) obtained from the cluster-based permutation analysis (see panel A).

Figure 7
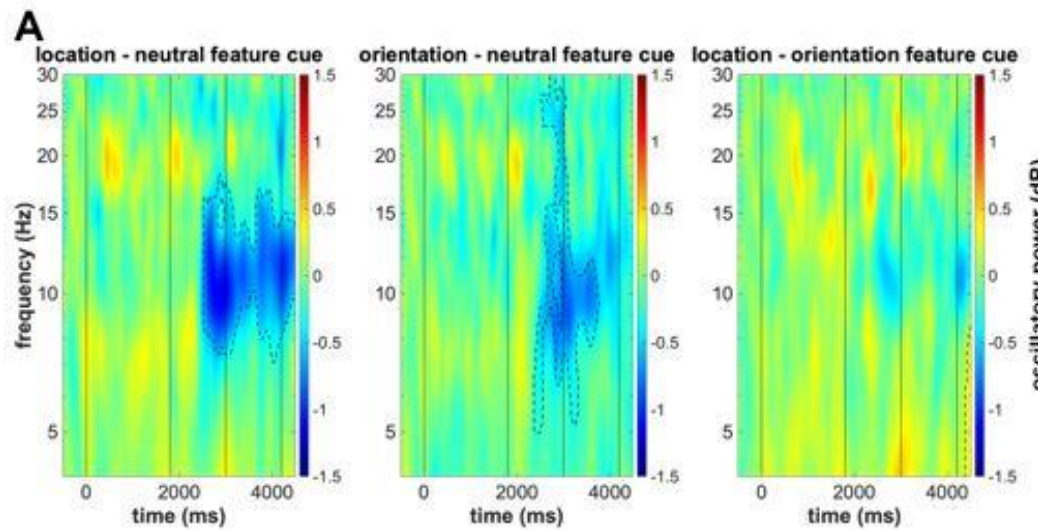

B scalp map: 33 ICs from 21 subjects

D
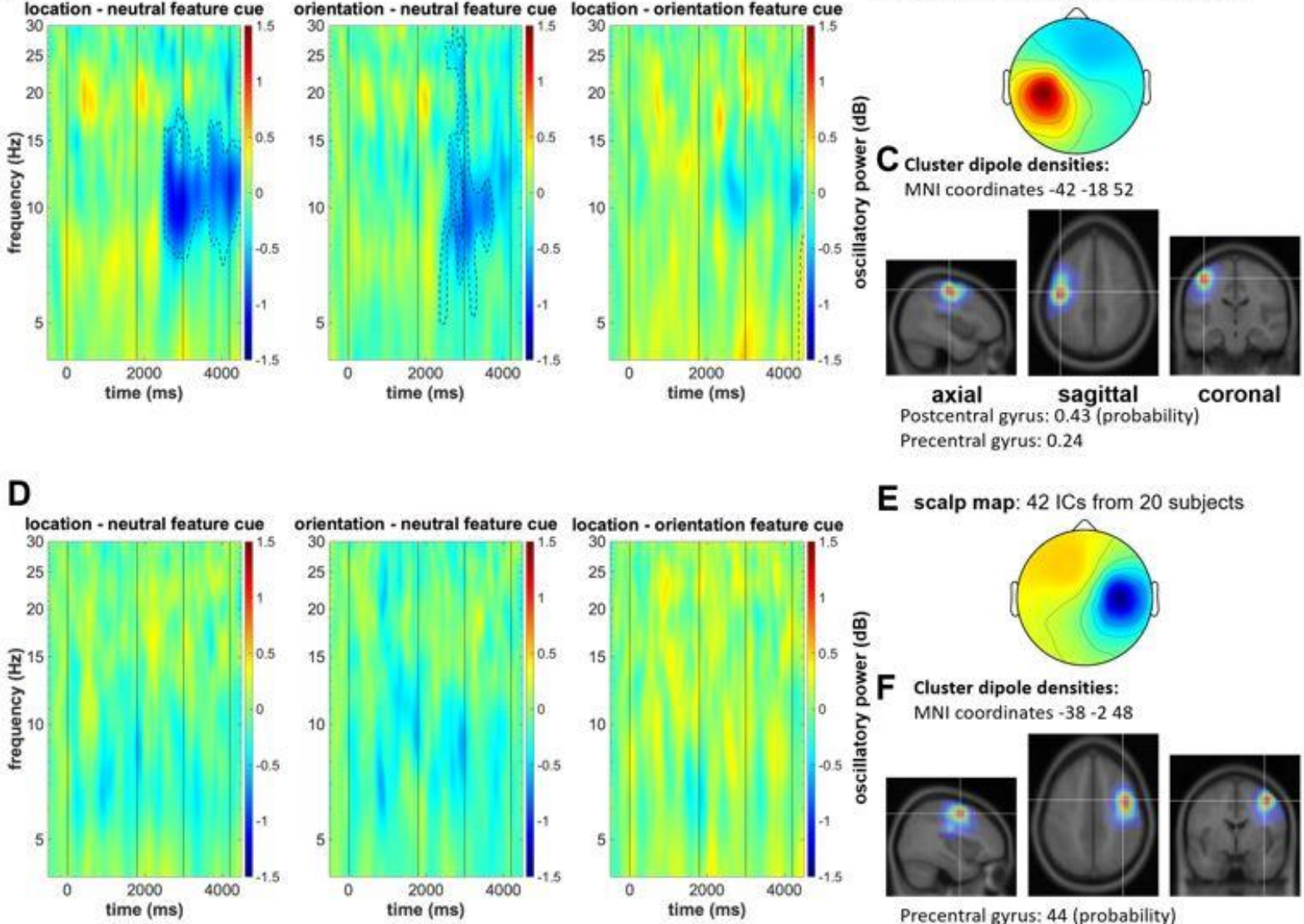

E scalp map: 42 ICs from 20 subjects

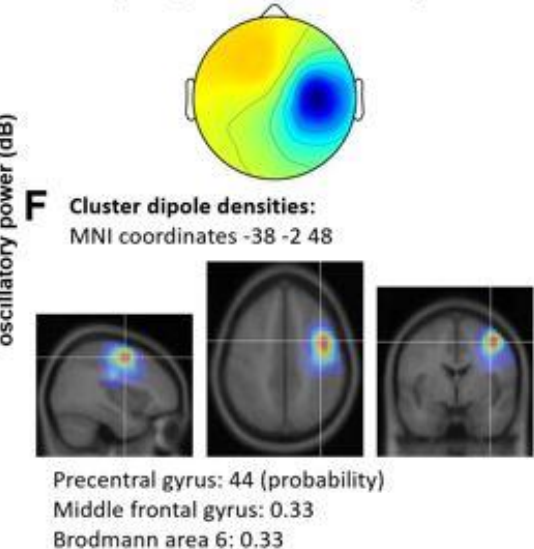

Figure 7. Feature cue effects for contralateral vs. ipsilateral mu/beta IC clusters (experiment

2). Panel A depicts the differences in oscillatory power for the contralateral IC cluster between the three feature cue conditions. Time-frequency clusters differing between the conditions are indicated by a dotted (--) line. Panel B shows the scalp map of the left-hemispheric IC cluster and Panel C the respective dipole densities. Panel $D$-F depict the same results for the right sensorimotor cortex. 
bioRxiv preprint doi: https://doi.org/10.1101/2022.01.25.477681; this version posted January 27,2022 . The copyright holder for this preprint (which was not certified by peer review) is the author/funder, who has granted bioRxiv a license to display the preprint in perpetuity. It is made available under aCC-BY-NC-ND 4.0 International license.

Figure 8


Figure 8. Task cue effects for contralateral vs. ipsilateral mu/beta IC clusters (experiment 2).

Panel A depicts the difference in oscillatory power between the three task cues for the left-hemispheric IC cluster. Time-frequency clusters differing between the conditions are indicated by a dotted (--) line. Panel B shows the spectral power for the left-hemispheric IC cluster. Panel C and D depict the same results for the right-hemispheric IC cluster. 


\section{Suppelementary}

A Outlier 2 (20 Ss, 37 ICs'
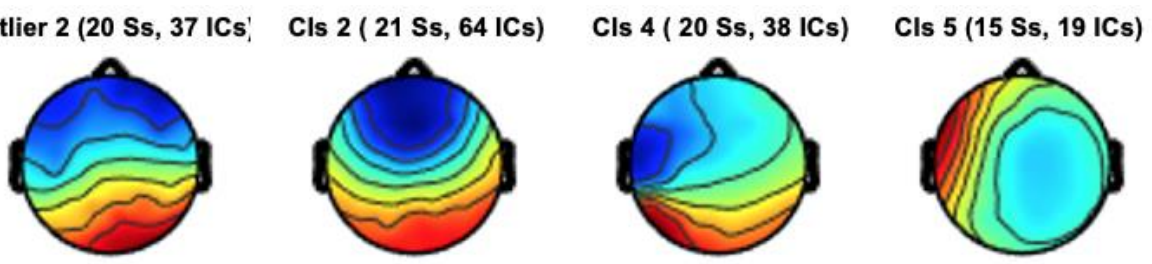

Cls 6 (15 Ss, 31 ICs)
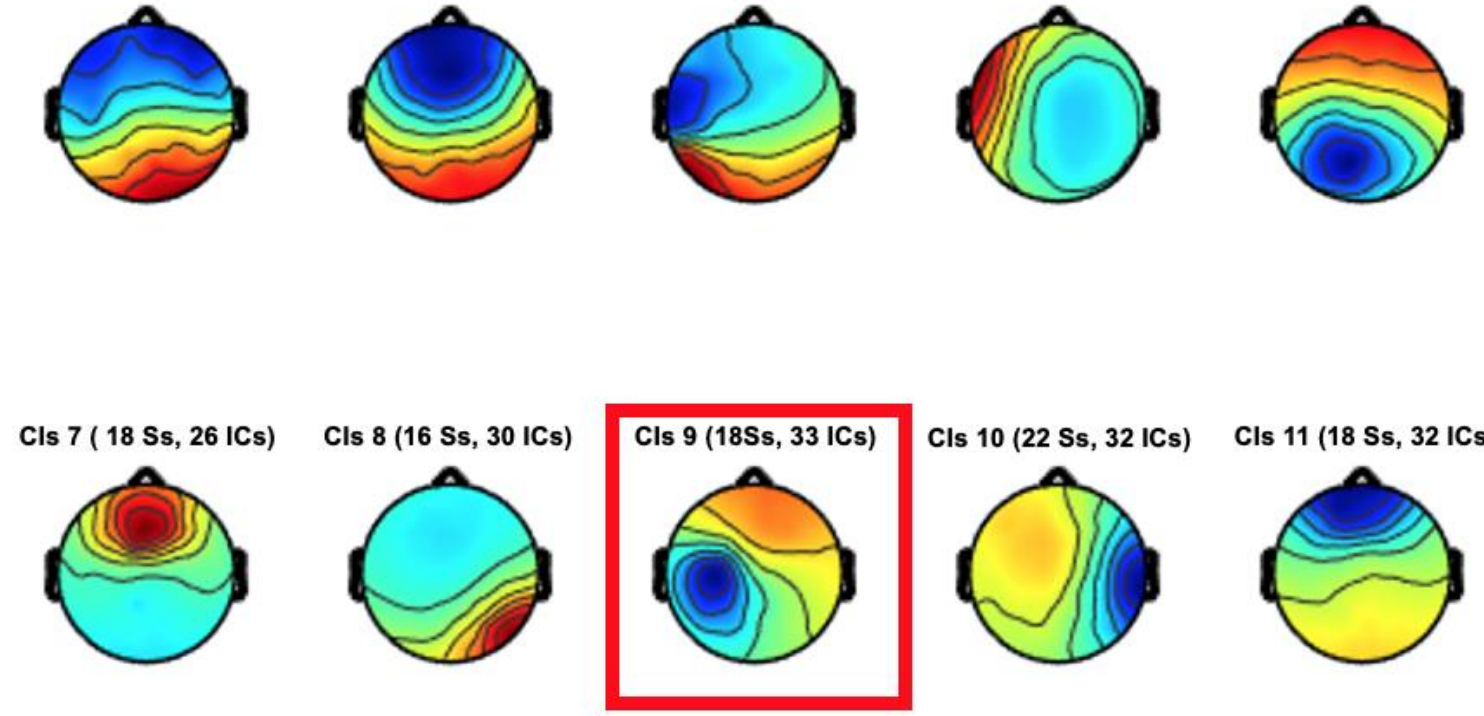

Cls 12 (19 Ss, 22 ICs)

Cls 13 ( $17 \mathrm{Ss}, 32$ ICs)
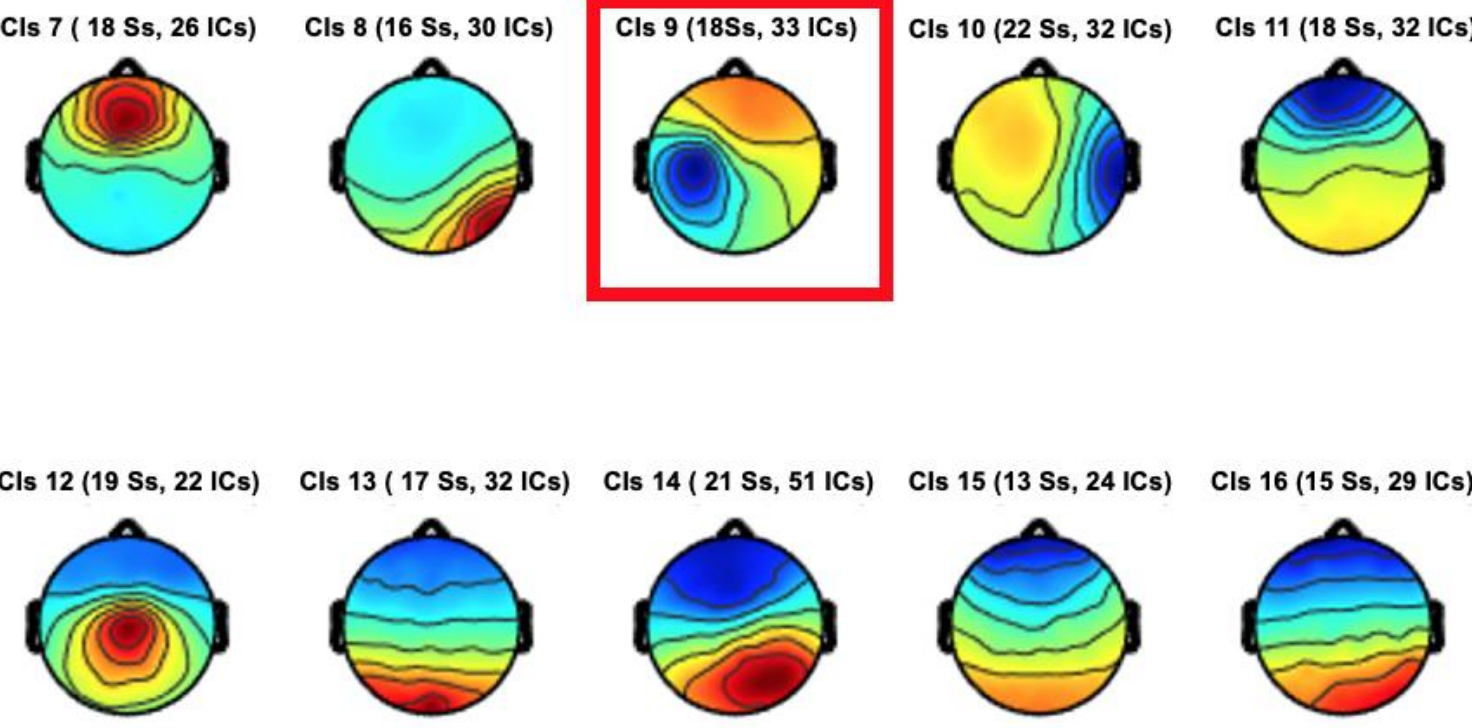

Cls 17 (15 Ss, 27 ICs)

Cls 18 (18 Ss, 37 ICs)
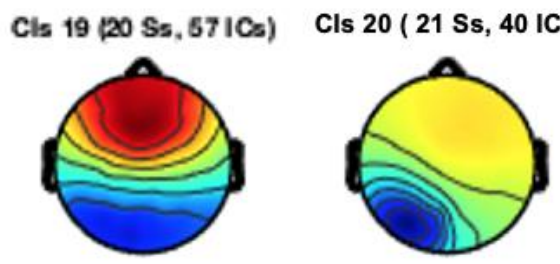

Cls 16 (15 Ss, 29 ICs)
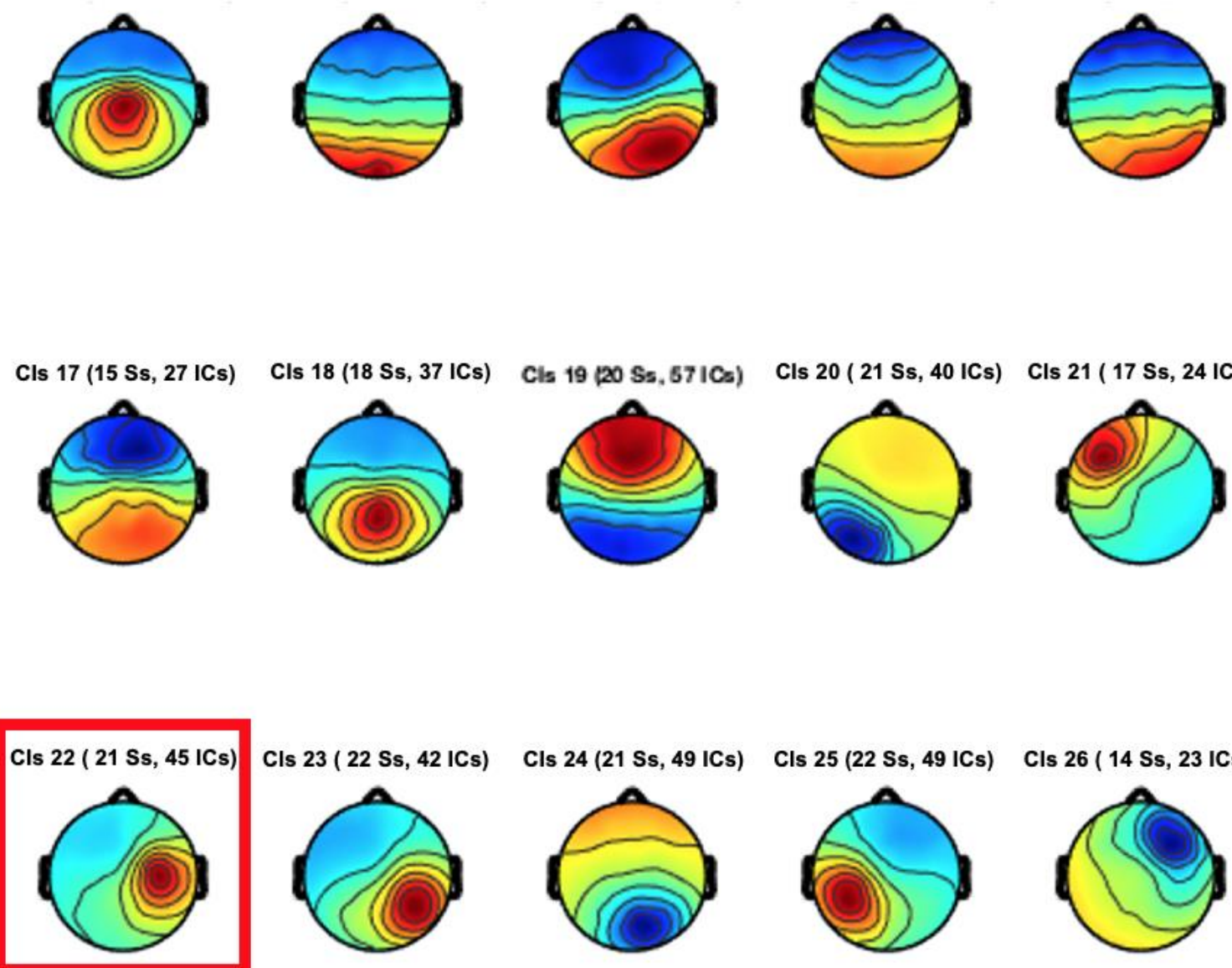

\section{Supplementary A. Scalp topographies of independent component clusters in experiment 1. Mean}

topographies of 24 IC clusters. The clusters representing left hemispheric and right-hemispheric 
bioRxiv preprint doi: https://doi.org/10.1101/2022.01.25.477681; this version posted January 27, 2022. The copyright holder for this preprint (which was not certified by peer review) is the author/funder, who has granted bioRxiv a license to display the preprint in perpetuity. It is made available under aCC-BY-NC-ND 4.0 International license.

mu/beta oscillatory activity are marked in red. The number of subjects (Ss) and ICs contributing to each cluster are given above each topography. In addition to the 24 clusters, the mean topography for the outlier cluster is provided in the top-left corner.

B

Outlier 2 (15 Ss, $34 \mathrm{ICs})$

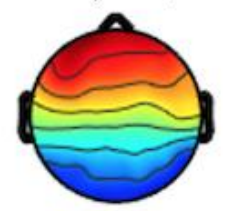

Cls 3 (18 Ss, 29 ICs)

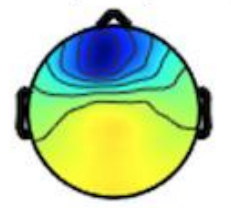

Cls 4 (13 Ss, 34 ICs)

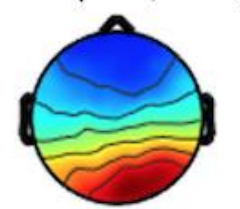

Cls 9 (13 Ss, 17 ICs)

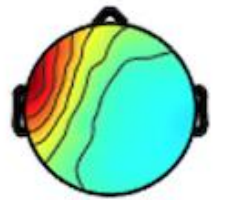

Cls 5 (17 Ss, 22 ICs)
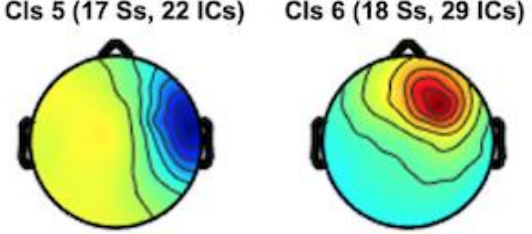

Cls 11 (17 Ss, 24 ICs)

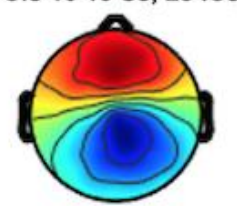

Cls 12 (21 Ss, 25 ICs)

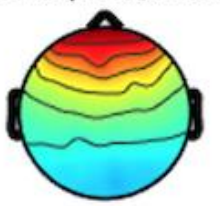

Cls 8 (16 Ss, 34 ICs)

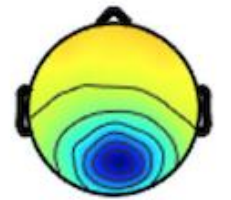

Cls 13 (15 Ss, 35 ICs)

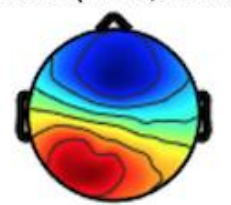

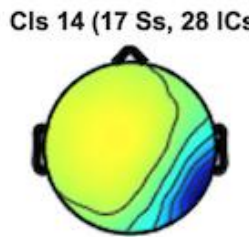

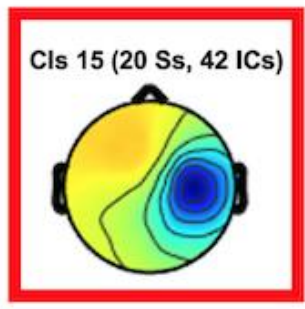

Cls 16 (21 Ss, 44 ICs)

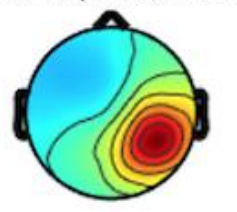

Cls 19 (15 Ss, 26 ICs)
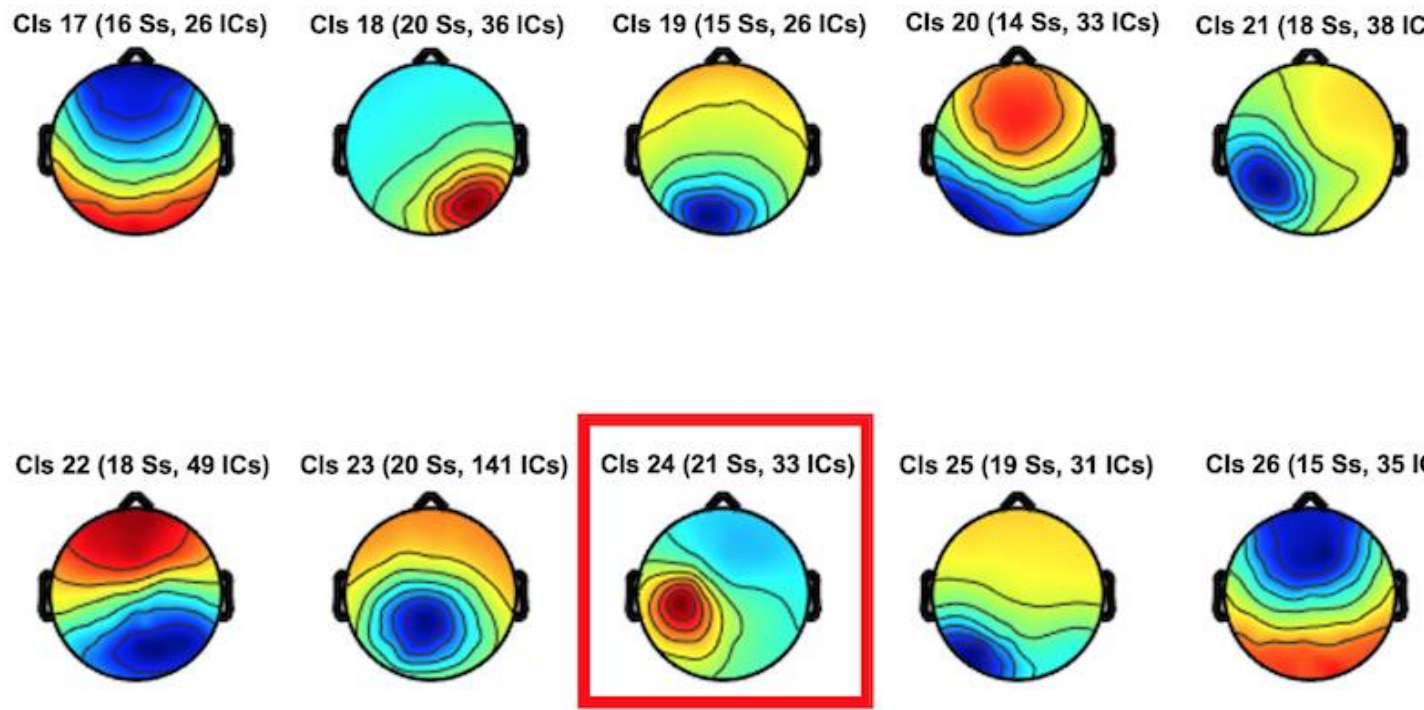

Cls 26 ( 15 Ss, 35 ICs)

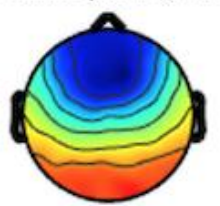


bioRxiv preprint doi: https://doi.org/10.1101/2022.01.25.477681; this version posted January $27,2022$. The copyright holder for this preprint (which was not certified by peer review) is the author/funder, who has granted bioRxiv a license to display the preprint in perpetuity. It is made available under aCC-BY-NC-ND 4.0 International license.

Supplementary B. Scalp topographies of independent component clusters in experiment 2. Mean

topographies of 24 IC clusters. The clusters representing left hemispheric and right-hemispheric mu/beta oscillatory activity are marked in red. The number of subjects (Ss) and ICs contributing to each cluster are given above each topography. In addition to the 24 clusters, the mean topography for the outlier cluster is provided 